Review article

\title{
Advances in bioinks and in vivo imaging of biomaterials for CNS applications is
}

\author{
Eduarda P. Oliveira a,b,c , Izabela Malysz-Cymborska ${ }^{\mathrm{d}}$, Dominika Golubczyk ${ }^{\mathrm{d}}$, Lukasz Kalkowski ${ }^{\mathrm{d}}$, \\ Joanna Kwiatkowska ${ }^{\text {d, Rui L. Reis }}{ }^{\mathrm{a}, \mathrm{b}, \mathrm{c}}$, J. Miguel Oliveira ${ }^{\mathrm{a}, \mathrm{b}, \mathrm{c}}$, Piotr Walczak ${ }^{\mathrm{d}, \mathrm{e}, \mathrm{f}, *}$ \\ a 3B's Research Group, I3Bs - Research Institute on Biomaterials, Biodegradables and Biomimetics, University of Minho, Headquarters of the European Institute of Excellence on \\ Tissue Engineering and Regenerative Medicine, AvePark, Parque de Ciência e Tecnologia, Zona Industrial da Gandra, 4805-017 Barco, Guimarães, Portugal \\ ${ }^{\mathrm{b}}$ ICVS/3B's - PT Government Associate Laboratory, Braga/Guimarães, Portugal \\ ${ }^{\mathrm{c}}$ The Discoveries Centre for Regenerative and Precision Medicine, Headquarters at University of Minho, AvePark, 4805-017 Barco, Guimarães, Portugal \\ ${ }^{\mathrm{d}}$ Dept. of Neurosurgery, School of Medicine, University of Warmia and Mazury, Olsztyn, Poland \\ ${ }^{\mathrm{e}}$ Russell H. Morgan Dept. of Radiology and Radiological Science, Johns Hopkins University, Baltimore, MD, United States \\ ${ }^{\mathrm{f}}$ Cellular Imaging Section and Vascular Biology Program, Institute for Cell Engineering, Johns Hopkins University, Baltimore, MD, United States
}

\section{A R T I C L E I N F O}

\section{Article history:}

Received 9 November 2018

Received in revised form 25 April 2019

Accepted 3 May 2019

Available online 8 May 2019

\section{Keywords:}

Stem cells

Brain

Bioprinting

Bioink

Imaging

\begin{abstract}
A B S T R A C T
Due to increasing life expectancy incidence of neurological disorders is rapidly rising, thus adding urgency to develop effective strategies for treatment. Stem cell-based therapies were considered highly promising and while progress in this field is evident, outcomes of clinical trials are rather disappointing. Suboptimal engraftment, poor cell survival and uncontrolled differentiation may be the reasons behind dismal results. Clearly, new direction is needed and we postulate that with recent progress in biomaterials and bioprinting, regenerative approaches for neurological applications may be finally successful. The use of biomaterials aids engraftment of stem cells, protects them from harmful microenvironment and importantly, it facilitates the incorporation of cell-supporting molecules. The biomaterials used in bioprinting (the bioinks) form a scaffold for embedding the cells/biomolecules of interest, but also could be exploited as a source of endogenous contrast or supplemented with contrast agents for imaging. Additionally, bioprinting enables patient-specific customization with shape/size tailored for actual needs. In stroke or traumatic brain injury for example lesions are localized and focal, and usually progress with significant loss of tissue volume creating space that could be filled with artificial tissue using bioprinting modalities. The value of imaging for bioprinting technology is advantageous on many levels including design of custom shapes scaffolds based on anatomical 3D scans, assessment of performance and integration after scaffold implantation, or to learn about the degradation over time. In this review, we focus on bioprinting technology describing different printing techniques and properties of biomaterials in the context of requirements for neurological applications. We also discuss the need for in vivo imaging of implanted materials and tissue constructs reviewing applicable imaging modalities and type of information they can provide.
\end{abstract}

\section{Statement of Significance}

Current stem cell-based regenerative strategies for neurological diseases are ineffective due to inaccurate engraftment, low cell viability and suboptimal differentiation. Bioprinting and embedding stem cells within biomaterials at high precision, including building complex multi-material and multi-cell type composites may bring a breakthrough in this field. We provide here comprehensive review of bioinks, bioprinting techniques applicable to application for neurological disorders. Appreciating importance of longitudinal monitoring of implanted scaffolds, we discuss advantages of various imaging modalities available and suitable for imaging biomaterials in the central nervous system. Our goal is to inspire new experimental approaches combining imaging, biomaterials/bioinks, advanced manufacturing and tissue engineering approaches, and stimulate interest in image-guided therapies based on bioprinting.

(c) 2019 Published by Elsevier Ltd on behalf of Acta Materialia Inc.

\footnotetext{
Part of the Cell and Tissue Biofabrication Special Issue, edited by Professors Guohao Dai and Kaiming Ye.

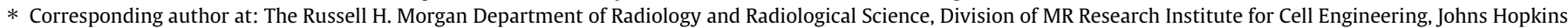
University School of Medicine, Broadway Research Building Rm 647, 733 N Broadway, United States.

E-mail address: pwalczak@mri.jhu.edu (P. Walczak).
} 


\section{Contents}

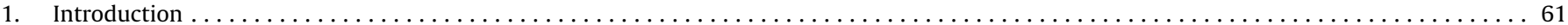

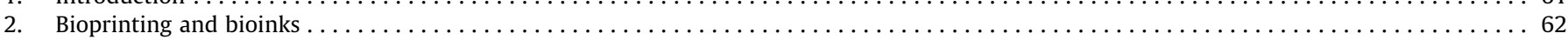

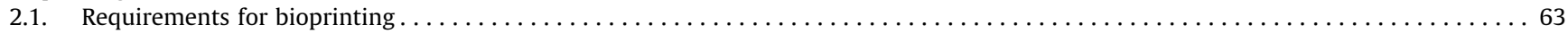

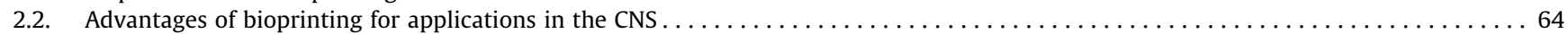

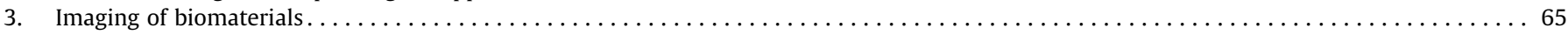

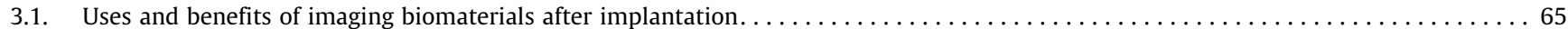

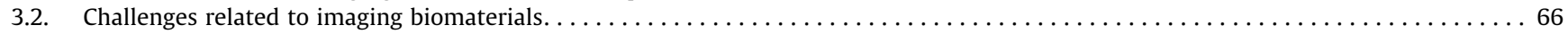

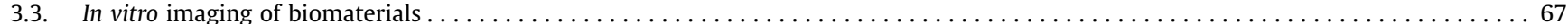

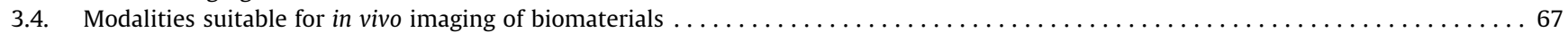

3.4.1. Bioluminescence. . . . . . . . . . . . . . .

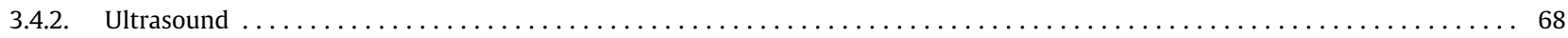

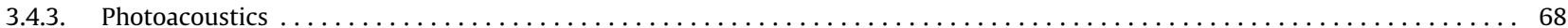

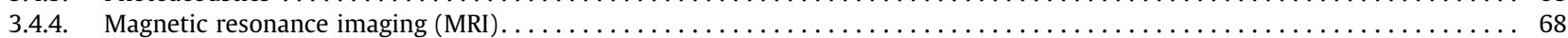

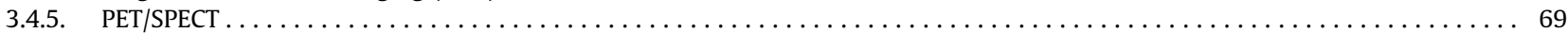

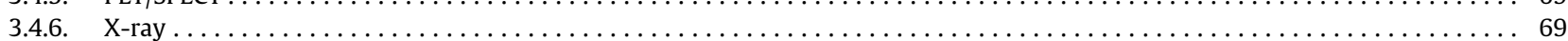

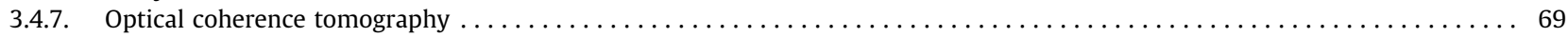

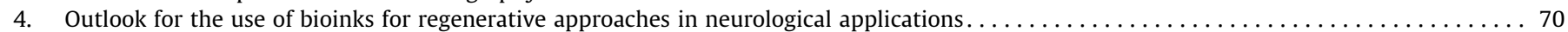

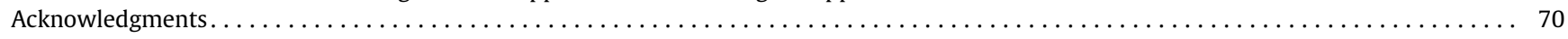

Disclosures . . . . .

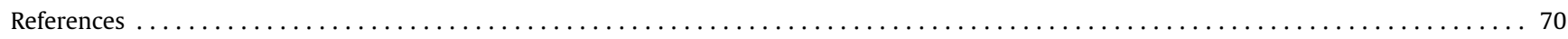

\section{Introduction}

Diseases of the central nervous system (CNS) are a leading cause of morbidity and long-term disability of adult population, burdening the health-care based economies worldwide [1,2]. Sedentary lifestyle and increasing life expectancy results in higher incidence particularly of cerebrovascular disease further exacerbating the problem [3]. Many of CNS diseases such as amyotrophic lateral sclerosis, Alzheimer's disease are characterized by disseminated or global pathology and as such are not good candidates for therapies involving bioprinting as it would be extremely challenging if not impossible to achieve global biodistribution of bioprinted scaffolds throughout the brain. Other diseases such as stroke or traumatic brain injury (TBI) are localized and focal, and in the course of disease process usually there is a loss of significant volume of neural tissue that is replaced by fluid or scar tissue. Such void of tissue is a significant obstacle to reparative processes as it has been reported for spinal cord injury. This scenario creates the proper opportunity for application of biomaterials and indeed significant effort has been directed towards implantation of materials that would bridge that gap and encourage axonal sprouting [4]. Due to the lack of regenerative capacity of the CNS cell-based therapies have been increasingly studied as approaches for treating different neurological diseases. Several therapeutic mechanisms have been reported including differentiation towards mature neural phenotypes [5] or trophic support to surviving cells, which boosts the endogenous recovery mechanisms [6,7]. However, significant drawback is related to low engraftment and survival of stem cells after administration, reducing or eliminating their therapeutic capacity $[8,9]$. Transplantation into disease-damaged tissue is particularly challenging as fragile stem cells are placed in highly hostile microenvironment. Combining stem cells with biomaterials is very attractive in this context as biomaterial may shield the cells from this unsupportive milieu [10] or even modify the microenvironment by releasing growth or anti-inflammatory factors [11,12]. Studies show that advantages of using cell-biomaterial composites are extensive including the control over the orientation of cells, enhanced cell viability, proliferation, adhesion [13], differentiation [14], directed migratory behavior [15] and even improved retention of their secretome (secreted bioactive molecules) [16], responsible for their beneficial paracrine functions [17]. Moreover, biomaterials can be tailored in terms of their structure, shape, physicochemical properties and biological performance, among others. Biomaterials offer the possibility to incorporate several functions within a single material, to produce multifunctional biomaterials. Some examples include the functionalization of the polymers (e.g., adhesion proteins [13]) and their combination with cells, genes and bioactive molecules (e.g., growth factors) [18]. Another interesting option is the incorporation of specific contrast agents (e.g. iron oxide nanoparticles for detection in MRI) that would allow longitudinal, non-invasive visualization of the scaffold when contrast agent is blended in the bioink [19] or visualization of embedded cells, when contrast is used as a cell label [20,21]. Cross-linking cations can also be exploited as imaging agent such as in case of manganese for alginate hydrogels. One of the drawbacks of traditional pre-cast or injectable scaffolds is high variability of end products. Bioprinting overcomes these limitations as it tailors produced materials precisely to the qualities of the local defect in terms of internal architecture and shape [22]. Bioprinting also allows the production of tissue analogues or brain models that would provide a platform for drug/scaffold screening with higher biomimetics with tissue-like 3D structure (3D) and cell-cell or cell-extracellular matrix interactions. Moreover, it is be possible to print these models with patients' own cells, providing a more reliable and relevant evaluation of the tested therapies [23].

CNS is comprised of highly specialized and fragile tissue, and, being sequestered behind the bone compartments it is very difficult to access thus monitoring status of implanted biomaterials and stem cells is challenging. Tissue biopsy available in other organ systems is not an option, due to the risk of complications [24]. These features were primary motivation for developing noninvasive imaging modalities for longitudinal monitoring. Such information about the location, degradation of the material and interactions with host tissue is essential for complete assessment of their therapeutic utility. It also provides key data for optimization of such systems for maximized therapeutic effect [25].

In this review we provide in depth analysis of recent developments in bioprinting, various available bioinks as well as non-invasive imaging strategies for monitoring of implanted biomaterials. With CNS being particularly demanding target we focused here on applications of biomaterials/bioinks in bioprinting and imaging for neurological applications. 


\section{Bioprinting and bioinks}

Conventional production techniques for 3D scaffolds can be accomplished by numerous methods, such as solvent casting, freeze-drying, micro-pores engineering and electrospinning. Nevertheless, these processes are poorly controlled resulting in high variability, namely batch to batch variability. They also have low adaptability to a particular injury site or disease, as customization of a scaffold's for each patient would be demanding and expensive [26]. Bioprinting techniques were inspired by the necessity of producing biofunctional 3D scaffolds with high reproducibility, in terms of internal architecture and shape (especially with blends). These techniques use a computer-aided design (CAD) software that offers versatility to easily customize the scaffolds to the patient's needs, as for example, a tissue defect [27]. 3D Bioprinting follows the same principles as regular 2D printers, but produces layers of biomaterial along the $\mathrm{Z}$ axis and is able to print various materials including living cells, allowing the production of 3D structures that are biologically active [28]. Several adaptations branched from the original 3D printing to better suit the demands, such as stereolithography, Inkjet, extrusion-based and laser-assisted bioprinting $[29,30]$. Overall features of these various techniques are schematically represented in Fig. 1 and Table 1.

Stereolithography is a technique that utilizes photo-responsive polymers/molecules that are polymerized during the printing process, using a light source, as for example a UV-light laser or visible light using computer-based control [31,32]. The laser is controlled using a digital micro-mirror and directed towards a tank below that contains resin, where the photo-crosslinkable polymer will be deposited and cured (polymerized) layer-by-layer to form the selected structure [33]. This technique allows for incorporation of molecules, nanomaterials (that are not light-sensitive) and cells (depending on the wavelength of the UV-light or other light source used). Additionally, unpolymerized material will maintain the liquid form, allowing to be easily washed away [8]. This technique can be performed in a focal manner (laser beam that scans along the biomaterial) or using Digital Light Processing (DPL)-based bioprinting where the bioprinted polymer layer is cured entirely at once (decreasing production time and avoiding artificial interfaces) $[2,34]$. Biomaterials are so versatile that is also possible to combine techniques for production of specific, customizable scaffolds, or to improve their characteristics, as for example stability or detail resolution. Lee's Group [15] developed a neural 3D scaffold with adjustable pore structure and embedded aligned fibers through the combination of stereolithography and electrospinning techniques, using polycaprolactone (PCL) and PCL mixed with gelatin as biomaterials. The team reported enhanced viability and proliferation of Neural Stem Cells (NSCs) in the fiber-containing scaffolds, and cultures of primary embryonic rat cortical cells showed higher density and length of newly formed neurites that were organized along the direction of the fibers.

Another technique is Inkjet bioprinting, where the bioink is sprayed over a biomaterial or culture dish, with picoliter precision, due to the computer-based control of the droplets. The inkjet printing process can be further divided into thermal (heat) or piezoelectric (voltage) methods depending on the type of force used to push the bioink out of the nozzle. However, the thermal method produces droplets with varying sizes, the nozzle often clogs and the heat can damage both protein-based inks and encapsulated cells [35]. The piezoelectric method does not clog the nozzle and is easier to print identical droplets, but the piezoelectric technology might cause damage to cell membrane or result in cellular lysis when fragile cells are used [36]. However, Lorber and colleagues [37] investigated, whether primary retinal cells and retinal glial
A. Stereolithography

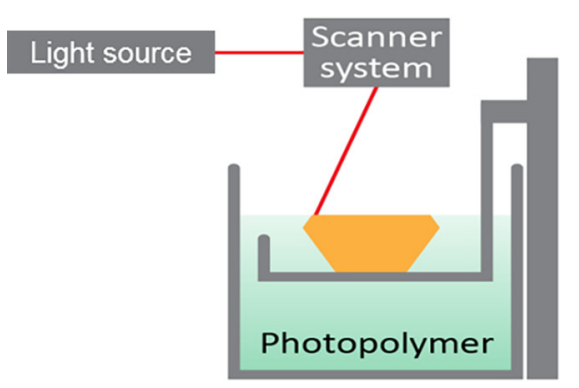

B. Laser-assisted bioprinting

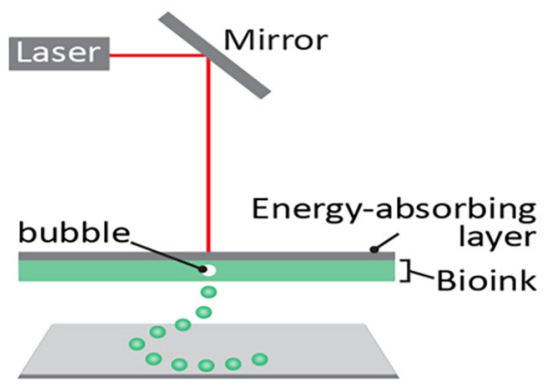

C. Inkjet bioprinting

Thermal inkjet Piezoelectric inkjet

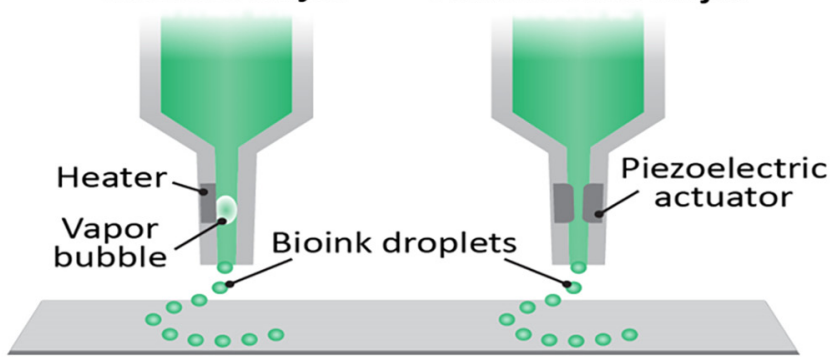

D. Extrusion-based bioprinting

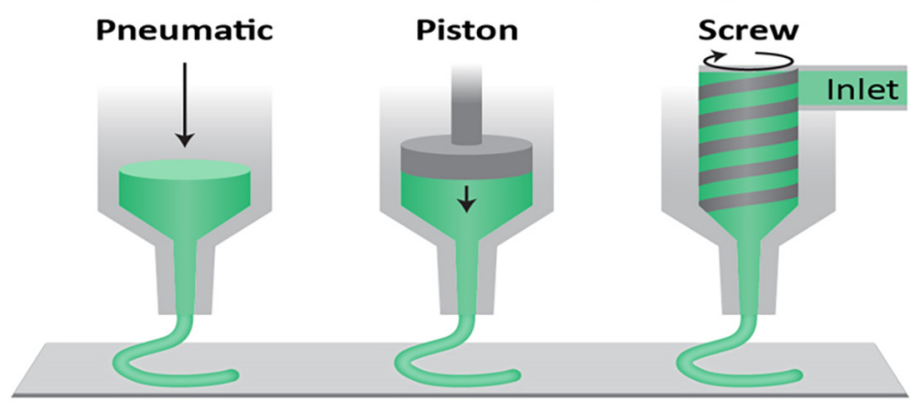

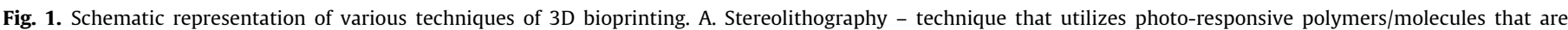

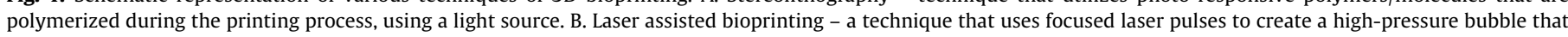

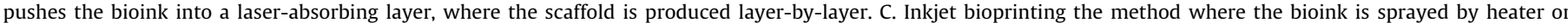

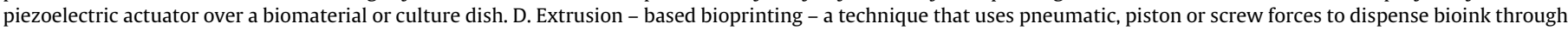
a nozzle that produces continuous streams of material. 
Table 1

Techniques used for 3D bioprinting.

\begin{tabular}{|c|c|c|c|c|c|}
\hline Method & Bioink used & Cell type & Advantage & Application & Refs. \\
\hline Micro-Extrusion & $\begin{array}{l}\text { Blend of alginate, agarose and } \\
\text { carboxymethyl-chitosan }\end{array}$ & $\begin{array}{l}\text { Cortical } \\
\text { neural stem } \\
\text { cells }\end{array}$ & $\begin{array}{l}\text { Biomaterial: Supports in situ hNSC expansion and } \\
\text { differentiation; } \\
\text { Technique: Adaptable to other neuronal and non- } \\
\text { neuronal constructs; Direct-write printing of cell- } \\
\text { laden bioink. }\end{array}$ & $\begin{array}{l}\text { Production of 3D artificial } \\
\text { neural tissue constructs. }\end{array}$ & {$[38]$} \\
\hline \multirow[t]{2}{*}{ Extrusion } & $\begin{array}{l}\text { RGD-modified low-acyl Gellan } \\
\text { Gum }\end{array}$ & $\begin{array}{l}\text { Primary } \\
\text { cortical } \\
\text { neurons }\end{array}$ & $\begin{array}{l}\text { Biomaterial: RGD-modification enhanced cell } \\
\text { viability and proliferation and promoted neural } \\
\text { network formation in } 5 \text { days; } \\
\text { Technique: Low-cost, no need for expensive } \\
\text { bioprinting equipment. }\end{array}$ & $\begin{array}{l}\text { Bioprinting of complex and } \\
\text { layered brain-like 3D } \\
\text { structures for modeling } \\
\text { disease. }\end{array}$ & [13] \\
\hline & $\begin{array}{l}\text { Alginate and gelatin slurry } \\
\text { support bath }\end{array}$ & $\begin{array}{l}\text { MC3T3-E1.4 } \\
\text { fibroblast cell } \\
\text { line }\end{array}$ & $\begin{array}{l}\text { Biomaterial: Possibility of producing a wide range } \\
\text { of soft tissue constructs, owed to the gelatin slurry } \\
\text { support bath; } \text { Technique: High resolution printing } \\
(\sim 200 \mu \mathrm{m}) \text { of anatomical structures such as frontal } \\
\text { and temporal lobes, cerebellum, cortex and its } \\
\text { major folds. }\end{array}$ & $\begin{array}{l}\text { Proof of concept of the FRESH } \\
\text { technology to produce high } \\
\text { resolution 3D printed soft- } \\
\text { tissue like models (brain and } \\
\text { heart). }\end{array}$ & [120] \\
\hline \multirow[t]{2}{*}{ Stereo-lithography } & $\begin{array}{l}\text { Blend of polyethylene glycol } \\
\text { diacrylate (PEG) and GelMA, } \\
\text { with an eosin Y-based } \\
\text { photoinitiator }\end{array}$ & $\begin{array}{l}\mathrm{NIH} / 3 \mathrm{~T} 3 \\
\text { fibroblasts }\end{array}$ & $\begin{array}{l}\text { Biomaterial: Supportive of cell survival/ } \\
\text { proliferation ( } 85 \% \text { viability for at least } 5 \text { days of } \\
\text { culture); } \\
\text { Technique: Custom-build and low-cost bioprinting } \\
\text { of curable hydrogels with visible-light; high speed } \\
\text { of production; high resolution }(50 \mu \mathrm{m}) \text {. }\end{array}$ & $\begin{array}{l}\text { Tissue engineering and } \\
\text { bioengineering for microscale } \\
\text { cell patterning. }\end{array}$ & [31] \\
\hline & $\begin{array}{l}\text { Electrospun fibers of blended } \\
\text { polycaprolactone and gelatin, } \\
\text { covered with polyethylene (PEG) } \\
\text { and PEG diacrylate (PEG-DA), } \\
\text { with photoinitiator not specified }\end{array}$ & $\begin{array}{l}\text { Neural stem } \\
\text { cell }\end{array}$ & $\begin{array}{l}\text { Biomaterial: Increased cell adhesion and } \\
\text { proliferation; Supported and directed the neurite } \\
\text { outgrowth; } \\
\text { Technique: Highly interconnected pores uniformly } \\
\text { along the entire structure. }\end{array}$ & $\begin{array}{l}\text { Bioprinting of highly aligned } \\
\text { scaffold for neural } \\
\text { regeneration. }\end{array}$ & [15] \\
\hline $\begin{array}{l}\text { Cryogenic processing } \\
\text { and extrusion }\end{array}$ & $\begin{array}{l}\text { Collagen coated hydrogel } \\
\text { composite of poly(vinyl) alcohol } \\
\text { (PVA) and Phytagel }\end{array}$ & $\begin{array}{l}\text { Primary } \\
\text { Dermal } \\
\text { Fibroblasts }\end{array}$ & $\begin{array}{l}\text { Technique: Bioprinting of complex soft-tissue like } \\
\text { structures; } \\
\text { Biomaterial: Mechanical response similar to brain } \\
\text { tissue (viscoelastic behavior in two strain rates). }\end{array}$ & $\begin{array}{l}\text { Constructs with complex } \\
\text { shape and precise geometries } \\
\text { (microstructure). }\end{array}$ & [121] \\
\hline Inkjet (Droplets) & Rat tail origin type I collagen (BD & $\begin{array}{l}\text { Embryonic } \\
\text { astrocytes } \\
\text { and neurons }\end{array}$ & $\begin{array}{l}\text { Biomaterial: Promoted astrocyte and neurons } \\
\text { viability and typical morphology; Supported } \\
\text { neurite outgrowth; } \\
\text { Technique: Allowed cell patterning and production } \\
\text { of scaffolds in single-layer or multilayer. }\end{array}$ & $\begin{array}{l}\text { Production of artificial 3D } \\
\text { neural tissue. }\end{array}$ & [38] \\
\hline
\end{tabular}

cells from rats, could be bioprinted by the piezoelectric method and whether their viability was affected by the process. They reported that both cell types could be bioprinted and they had no significant differences in survival or in neurite outgrowth, when compared to unprinted cultures with the same cell density. They also observed an improvement in the neurite density and elongation, showing the process did not affect their function.

Another approach is extrusion-based bioprinting, where the hydrogel (bioink) is rapidly extruded with precision into a liquid medium. This technique uses solutions/suspensions that are initially viscous but during the printing process decrease their viscosity, due to the shear stress provoked by the nozzle (shear thinning behavior). This can possibly produce flexible scaffolds with increased or decreased mechanical properties (elastic modulus), depending on the type polymer/crosslinker/concentration used $[38,39]$. Nevertheless, the viscosity of bioink must be adjusted to allow a clean printing without clogging, making this technique time consuming, and the resolution of produced materials is considered inferior than, for example, laser-assisted bioprinting. This latter technique uses focused laser pulses to create a highpressure bubble that will push the bioink into a laser-absorbing layer (made of gold or titanium), termed the collector substrate, where the scaffold will be produced layer-by-layer. This bioprinting process is used most frequently because it produces materials with high resolution and spatial distribution in both liquid and solid forms, at microscale range, being able to deposit a single cell per droplet. Additionally, as a nozzle-free technique it allows the incorporation of higher cell densities than remaining techniques, but at the same time is considered as expensive and depending on the laser applied, the cell viability can be affected (e.g. nanosecond laser irritation). Femtosecond lasers are preferably applied to bioinks containing delicate cells [40]. The bioprinting field offers an array of techniques to be adapted to the specific purpose, but especially to the physicochemical characteristics of the bioinks and also the cells to be used [41].

\subsection{Requirements for bioprinting}

The ink used in bioprinting, termed the bioink, can be selected and optimized to resemble the biological properties of the target tissue and this further increases the applications of bioprinting. Bioinks are mostly produced from biomaterials in hydrogel form containing therapeutic molecules such as glial scar-inhibiting/ breaking molecules [42], neurotrophic and/or angiogenic factors, among others [43]. These scaffolds can also contain cells of interest of various origins and characteristics, such as patient-derived (autologous) cord blood-derived Mesenchymal Stem Cells (MSCs) [44] or off-the-shelf (allogeneic) sources such as neuronal [45] or glial [46] progenitors. MSCs are by far the most frequently tested cell type and beneficial effects are exerted through their paracrine actions on neighboring cells, making them excellent candidate for embedding in biomaterials [47]. Another important approach with biomaterials is to biomimic the CNS extracellular matrix (ECM), known to be involved in several biological functions (e.g. adhesion, aligned growth, differentiation) in both physiological and pathological scenarios. For example, Lee and coworkers combined stere- 
olithography and electrospinning techniques to produce a 3D neural tissue construct, composed by gelatin/PCL fibers that were covered by a bioprinted PEG bioink. The improved biocompatibility and mechanical properties of this construct significantly enhanced viability, adhesion and proliferation of the encapsulated primary cortical neurons when compared to the bioink alone. Moreover, the produced scaffolds promoted higher number of neurites, which had higher length and extension (regarding the controls), and the newborn neurites extended along the fibers (directing their growth) [15]. Nervous system ECM-derived molecules, such as laminin, fibronectin, and collagen have been reported to promote cell adhesion and neurite/axon outgrowth, which is understandable as the cells recognize the ECM and react accordingly $[1,8]$.

The bioinks used during the bioprinting process are crosslinking during or immediately after printing, to ensure the intended shape and/or structure is produced. Bioprinting of cells without exogenous biomaterial (scaffold-free) is also possible, where cells are seeded layer-by-layer to obtain cellular structures in a process similar to embryonic development (e.g. tissue analogues) [48]. Bioinks need to possess certain properties, as for example the appropriate viscosity that allows a flowing extrusion, but upon reaching the surface/collector maintains the intended shape and gellifies accordingly. The mechanical properties of used hydrogels will influence both the printability and the cell effects (viability, proliferation and differentiation), as they react and modulate their functions accordingly [2]. The more similar the construct is to the native tissue in terms of, molecules present and/or cells used the higher the probability of scaffold's successful integration. A reported difficulty of scaffolds, both traditional and bioprinted, is the mimicking of in vivo elastic moduli stiffness (nervous tissue has a low elastic moduli) [49]. A study by Budday and coworkers [50] quantified the mechanical properties of both gray and white matter of a cows' brain, using the flat-punch indentation method. They described that the white matter had an average modulus of $1.895 \mathrm{kPa} \pm 0.592 \mathrm{kPa}$, being $39 \%$ stiffer than the gray matter, which had and average modulus of $1.389 \mathrm{kPa} \pm 0.289 \mathrm{kPa}$. The white matter has a more viscous consistency than the gray matter and had a less rapid response to the mechanical loading. But most importantly, the group reported that the white matter had higher regional variations, indicating that is a more anisotropic and heterogeneous tissue than the gray matter. This highlights the need for adapting the scaffolds' final mechanical properties in order to match the mechanical properties of the tissues aimed to be regenerated, i.e. as in the case of CNS, soft biomaterials are desired. The advantage of bioprinting techniques is that they allow an easy adaptation of the scaffolds using the CAD software [26].

One important and desired feature is that the scaffold should be biodegradable and have adjustable degradation rate to fit the intended purpose. When filling a cavity after loss of tissue the scaffold is usually adjusted for degradation rate to match the speed of newly formed tissue, with the aim of ultimately replacing the scaffold with functional tissue [21]. If the scaffolds degrades too quickly it will result in loss of cell/scaffold function before the tissue could recover/repair, if it takes too long to degrade the scaffold itself can function as a barrier for the repair/recovery. Finding the right bioink is a complex process, as the production or the biomaterial's concentration or viscosity that best suits the bioprinter can be deleterious and/or not beneficial for the survival or the density of encapsulated cells. Also, the bioink formulation sometimes need to be adapted depending on the requirements of the bioprinting process used. For example for laser-based or inkjet techniques more liquiform bioink is preferred, while the extrusion process requires a bioink with higher viscosity [8]. Park and co-workers [51] documented their analysis of the best bioink, in terms of printability and cell viability, for tissue engineering applications in soft tissues. They documented the variations in viscosity, printability, stability post-printing and cell survival were different depending on simply the molecular weight of biomaterial used. By rheological studies they discovered that it influences mechanical properties of the scaffold and its structural stability, as for example the hydrogels with higher ratio of high MW alginate were more viscous, allowing the production of more precise structures. However, highly viscous solutions made it difficult to control the printing process as they tend clog the nozzle and/or obstruct the flux, resulting in roughly made structures with undefined or unwanted architectures. Additionally, the printing of these solutions requires more forces to extrude the bioink through the nozzle, which will originate shear stress on encapsulated cells and lower their viability [52]. On the other hand, solutions that are more liquiform can also cause problems because printed structures might not hold their shape upon printing, or produce weak structures with inaccurate architectures. Also, because the liquid-to-gel transition is slow spatial distribution of embedded cells and overall homogeneity of the bioink can be compromised [48]. One strategy to overcome this includes combining polymers, where one polymer would improve the biological performance (aid in scaffold integration or viability of encapsulated cells) and another to provide the adequate mechanical properties. The mechanical properties of the bioink besides influencing the printing process are also very relevant for function/viability/proliferation of embedded cells and also for the successful integration of the scaffold $[39,53]$. Another important requirement is to preserve the good quality of embedded cells (viability and function) throughout the production process, as for example the shear stress of the printing process may be detrimental. This is particularly important when using sensitive cells, such as neural stem cells or mature neural phenotypes. Moreover, the materials must be biocompatible with target tissues (biomimic soft tissues) and cannot be immunogenic or toxic, to both host and transplanted cells. Lastly, the production and printing process has to be cost-effective and fairly easy for the user, facilitating also the translation to the clinical setting $[23,54]$.

\subsection{Advantages of bioprinting for applications in the CNS}

Bioprinting allows the control of spatial deposition and organization of the molecules/cells/biomaterials layer-by-layer, allowing the fabrication of complex structures with precise architectures, starting from the bottom up [2]. Additionally, it is possible to work with several types of biomaterials at the same time (e.g., bioprinters with multi-nozzles) and different cells, allowing production of materials better mimicking features of native tissues, which are hierarchically organized [54]. This is especially interesting for brain applications as it produces more realistic and dynamic neural microenvironments, by allowing the control over cell-cell and cell-biomaterial interactions [40]. Lozano's group [13] showed for example the possibility of printing 3D brain-like structures with layered architecture using RGD-GG bioink and encapsulated primary cortical neural cells to produce a more authentic representation of in vivo environment. They report that cells developed neuronal networks in less than 5 days post-printing with complex multi-layered structure of cerebral cortex. Moreover, the process can be adjusted to include other cell types and can be performed simply in a laboratory that has cell culture facilities. Jia and coworkers [39] produced a gelatin methacrylated, sodium alginate and 4arm poly(-ethylene glycol)-tetra-acrylate (PEGTA) bioink used in multilayered coaxial extrusion to produce vascular constructs. The bioink was first ionically crosslinked and afterwards covalently photocrosslinked to produce 3D perfusable hollow tubes. The produced constructs were shown to be supportive for the survival and proliferation of encapsulated human umbilical vein endothelial cells (HUVECs) and mesenchymal stem cells (MSCs), which lead to the formation of highly organized vessel-like structures. The 
computer-based extrusion through a mechanically managed nozzle/needle insures consistency and precision in the, production and physical properties of the scaffold (e.g. geometry, pore size) [55]. This ability to pre-program the 3D structures (both interior and surface) from previously acquired images (e.g., CT scan and MRI) before printing may allow a personalized treatment that increases the chances of scaffold integration and success. Fu and co-workers [27] successfully produced a cavity-specific scaffold, using anatomical data previously acquired from magnetic resonance of rat brain injuries. Using a CAD software they produced a collagen-chitosan scaffold with good printability, mechanical stability and degradation rate that can be quickly adapted to different defects. The scaffold had channels interconnected orthogonally to better mimic neural milieu and murine neural stem cells cultured in vitro were viable and extended neurites along the scaffold with connection to other neurites. The degradability of the scaffold in vivo was tested in rat and 12 weeks post-implantation the scaffold only lost $10 \%$ of weight. An interesting advantage of bioprinting is the production of complex and specific 3D architectures, as for example vascular constructs, which are essential players in the regeneration of neural tissue. Indeed, Jia and coworkers [39] produced 3D vascular structures with precise architectures, made from gelatin methacryloyl, sodium alginate and 4-arm poly(-ethylene glycol)-tetra-acrylate (PEGTA), using a coaxial extrusion technique (nozzle with two injection channels). The tubes were biocompatible and were able to support the survival and proliferation of MSCs and HUVECs cultures. Moreover, at 21 days of culture the cells secreted CD31 (endothelial-specific adhesion protein) and $\alpha$-SMA (actin isoform of vascular smooth muscle cells) and matured into a network similar to early-stage native vasculature.

Bioprinting also allows the production of scaffolds stratified into layers of different biomaterials, cells and molecules or to produce structures with increasing/decreasing biochemical or stiffness gradients. For example Lee and colleagues [18] printed a double-layer 3D scaffold, composed by layers of collagen hydrogel with encapsulated murine NSCs (C17.2 line) and Vascular Endothelial Growth Factor (VEGF)-releasing fibrin hydrogel. The printed cells presented a viability equivalent to manually seeded cells and were observed to migrate towards the fibrin-containing zone upon which their morphology changed. None of these phenomena were observed in the controls of only fibrin hydrogels or when the VEGF was printed together with or above the collagen. This study highlights the complexity that can be achieved with bioprinting, the numerous possibilities it offers and the importance of cellbiomaterial, cell-cell or cell-molecule interactions for the success or failure of the approach. Biomaterials coupled with this technique make possible to enhance performance of embedded cells including their survival, differentiation and functional integration. For example Zhu and coworkers [22] developed a printable bioink of gelatin methacrylamide (GelMA) that contained bioactive nanoplatelets of graphene, to produce neural scaffolds by stereolithography-based bioprinting. The promising structures were easily printed, homogenous and stable with precise architectures. Seeded neural stem cells had good viability, proliferation and preferentially differentiated into $\beta$-tubulin III-expressing neurons instead of GFAP-expressing astrocytes. These neurons exhibited elongated neurites at 14 days of cultures.

Currently bioprinting is mostly used for drug or device testing in printed models (in vitro) that mimic neural tissues (e.g. organ analogues [56]), reducing the ethical concerns of animal testing [23]. For example Lozano and co-workers [13] developed a handheld bathless bioprinting technique that allows creating 3D structures and bioprinted brain-like structures, made from intercalated layers of RGD-modified Gellan Gum containing primary cortical neurons or only hydrogel. This technique for reactive printing processes can be used in conventional cell culture facilities without needing highly specialized equipment. The cells cultured in the scaffold presented high viability and proliferation and were able to form an interconnected neural network. The scaffold also presented an adequate internal porosity that allowed oxygen and molecule exchange homogenously, as both the cells in the periphery as the cells in the center had similar densities and organizations. Moreover, the technique is not expensive and simple to reproduce in any laboratory with a cell culture facility, making it an appealing in vitro model to accurately study the behavior of brain cells, both in normal and pathological conditions. Additionally, this technique can be used to increase the feasibility of therapies, especially in cases where the patients' own cells could be used to test the efficacy of therapies or the same cells would be transplanted, avoiding immune problems and host rejection [57]. In a study Qi Gu [38] and co-workers were able to produce a 3D neural mini-tissue construct, by micro-extrusion bioprinting, composed of human cortical neural stem cells (hNSCs) encapsulated in a bioink of Alginate, carboxymethyl-chitosan and agarose. The biomaterial gelifies quickly to form porous, stable and tissue-like consistency structures that enable cell survival, their growth and in situ differentiation into functional neurons and supportive glial cells, as confirmed by immunocytochemistry and RT-qPCR. Interestingly, the neurons expressed GABAergic, astrocyte and oligodendrocytes markers and their extensive neurites formed synaptic contact points and established functional networks. Moreover, these neural networks were synaptically active, as shown by calcium imaging, gene analysis and immunostaining studies. The authors refer this construct is amenable to adaptations, for example the use of other cell types or adding biomolecules to induce differentiation of embedded cells into a specific lineage. The neural mini-tissue construct can be used in drugscreening assays, as an in vitro model for neuronal development or disease or perhaps as a tissue engineering approach for CNS recovery. In another study, Hsieh and group [58] used thermoresponsive water-based dispersions that formed structures at $37^{\circ} \mathrm{C}$ without needing crosslinkers and could be simply adjusted by the solid content present in the dispersion. The polyurethane solution containing murine NSCs allowed a clean printing and maintained cell viability and proliferation, as confirmed by in vitro assays. Moreover, upon implantation in an adult zebrafish with a traumatic brain injury, the 3D printed scaffold reduced the mortality rate and rescued the locomotion of the fishes (coordinated swimming with increased speed), showing potential for brain regeneration strategies. Researchers believe that with the current growth and advance of this technology, it will be possible to produce fully functional organs someday in the near future, giving hope for patients suffering from neurological disorders [23].

\section{Imaging of biomaterials}

\subsection{Uses and benefits of imaging biomaterials after implantation}

Technological advances in bioprinting enable production of complex structures, including customized shapes and sizes, creating artificial tissues resembling mechanical properties of target organs or even site-specific artificial tissue architecture. This initial step of production tissue composite is critical; however, therapeutic success depends on many downstream steps including their accurate deployment in the body, long-term retention or when desired, appropriate rate of degradation. It is also important to gain insight into interactions of implanted biomaterial and surrounding tissue as well as tracking the status of cellular components embedded within the scaffolds. Benefits from monitoring the abovementioned processes non-invasively over time without the need for biopsy are quite clear and that was the motivation for develop- 
ing suitable imaging techniques [24,59]. Several imaging modalities and contrast-detection mechanisms are available, which are very well suited for obtaining specific information about the biomaterials including anatomical, structural and molecular signature over time. Proton MRI and CT are superior for depicting anatomical information including placement, biodistribution of the material or interface between the material and the surrounding tissue. Molecular information such as degradation of individual tissue component or local $\mathrm{pH}$ can be detected with innovative molecular MRI techniques such as CEST MRI [60]. PET imaging, with its exquisite sensitivity, allows for monitoring metabolic activity within the scaffold [61] or drug release [62]. Comprehensive description about applications of these and other imaging modalities for monitoring biomaterials is provided in relevant sections below. Overview of various imaging techniques is schematically represented in Fig. 2 and examples are shown in Table 2.

\subsection{Challenges related to imaging biomaterials}

Considering the type of hydrogel, its physicochemical properties, and the specifics of the target tissue, different imaging modalities should be considered. While imaging biomaterials in vitro, prior to their implantation, is feasible and well established, tracking of materials inside the organism is more challenging. Imaging is expected to provide a breadth of information about the biomaterial itself, the embedded cells, and the graft-tissue interactions in the context of the healing process [25]. Moreover, it is important that imaging requirements, such as incorporation of the contrast agent, does not alter the properties of the biomaterial, does not interfere with biology of embedded cells, and, ideally, does not compromise functional assessment by any imaging modalities [63]. The selection of the optimal imaging technique for a particular application is not a trivial task, and multiple factors have to be

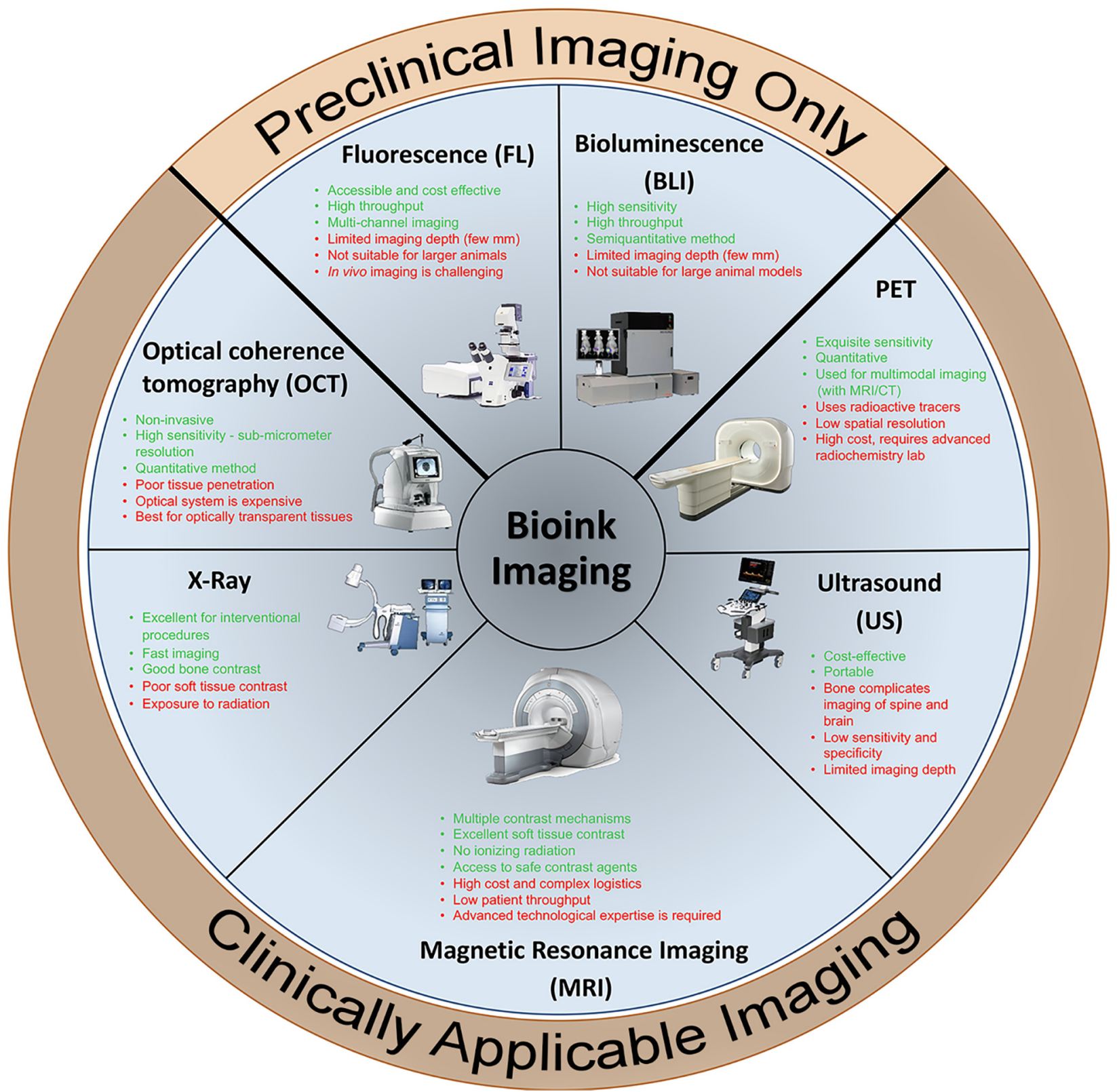

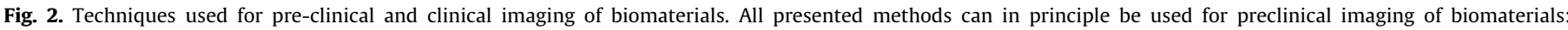

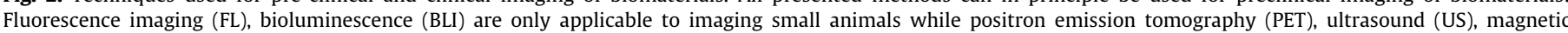
resonance imaging (MRI), X-ray and optical coherence tomography (OCT) are clinically applicable. 
Table 2

Imaging modalities of bioprinted biomaterials.

\begin{tabular}{|c|c|c|c|c|c|c|}
\hline Technique & Bioink & Cell type & Imaging & Application & Advantage & Refs \\
\hline Laser-based & Rat tail collagen type I & $\begin{array}{l}\text { MPIO-labelled } \\
\text { Stem cells from } \\
\text { Apical Papilla } \\
\text { (SCAPs) }\end{array}$ & MRI & $\begin{array}{l}\text { Detection (post mortem) } \\
\text { of cells' patterns after } \\
\text { in situ bioprinting onto a } \\
\text { mouse calvarial defect. }\end{array}$ & $\begin{array}{l}\text { Biomaterial: Supported cell } \\
\text { survival for } 7 \text { days } \\
\text { Technique: sensitivity of cell } \\
\text { detection (nearly single cells) }\end{array}$ & [122] \\
\hline Stereo-lithography & $\begin{array}{l}\text { Blends of PEGDA and GelMa } \\
\text { (with lithium phenyl-2,4,6- } \\
\text { trimethylbenzoylphosphinate } \\
\text { photoinitiator) }\end{array}$ & $\begin{array}{l}\text { GFP-labelled } \\
\text { neural stem cells }\end{array}$ & $\begin{array}{l}\text { Confocal } \\
\text { fluorescence } \\
\text { imaging }\end{array}$ & $\begin{array}{l}\text { Production of CNS } \\
\text { biomimetic structures for } \\
\text { rat spinal cord injury } \\
\text { repair. }\end{array}$ & $\begin{array}{l}\text { Biomaterial: Supported cell } \\
\text { survival and promoted axonal } \\
\text { growth (both host and graft); } \\
\text { Technique: Fast, scalable } \\
\text { production of patient-specific } \\
\text { scaffolds }\end{array}$ & [123] \\
\hline $\begin{array}{l}\text { Photo-lithography/soft- } \\
\text { lithography }\end{array}$ & $\begin{array}{l}\text { Rat tail collagen type I } \\
\text { (injection moulding into a } \\
\text { PDMS stamp made with epoxy } \\
\text { resins) }\end{array}$ & $\begin{array}{l}\text { GFP-expressing } \\
\text { endothelial cells }\end{array}$ & $\begin{array}{l}\text { Confocal } \\
\text { fluorescence } \\
\text { imaging }\end{array}$ & $\begin{array}{l}\text { 3D scaffold for vascular } \\
\text { regeneration and in vitro } \\
\text { model for drug screening }\end{array}$ & $\begin{array}{l}\text { Biomaterial: Production of } \\
\text { functional endothelium with } \\
\text { viable and living cells (with } \\
\text { angiogenic remodeling and } \\
\text { appropriate cell-cell junctions); } \\
\text { Technique: Allows vascular } \\
\text { analysis, namely endothelium } \\
\text { diffusivity/permeability and } \\
\text { testing of angiogenic/thrombotic } \\
\text { response }\end{array}$ & [124] \\
\hline Extrusion & $\begin{array}{l}\text { Blends of PEGTA, GelMa and } \\
\text { Alginate (with } \\
\text { sulforhodamine } 101 \\
\text { cadaverine) }\end{array}$ & $\begin{array}{l}\text { Human umbilical } \\
\text { vein endothelial } \\
\text { cells (HUVEC) and } \\
\text { mesenchymal } \\
\text { stem cells }\end{array}$ & $\begin{array}{l}\text { Fluorescence } \\
\text { imaging }\end{array}$ & $\begin{array}{l}\text { Bioprinting of perfusable } \\
\text { and highly ordered } \\
\text { vascular constructs for } \\
\text { vascularized tissues } \\
\text { replacement and repair. }\end{array}$ & $\begin{array}{l}\text { Biomaterial: promoted cell } \\
\text { viability and proliferation to form } \\
\text { an highly organized vessels; } \\
\text { Technique: Bioprinting of } \\
\text { complex 3D vasculature; } \\
\text { Mimiking of early vascular } \\
\text { maturation }\end{array}$ & [39] \\
\hline
\end{tabular}

considered. One example is the case of a superficial injection within a few millimeters under the skin, where optical imaging method (e.g. photoacoustic, fluorescent, bioluminescent) is sufficient to track hydrogel integrity and release of therapeutics within the injected organism [64,65]. However, to monitor materials within deep structures, such as intrathecal space around the spinal cord, tomographic techniques (e.g. MRI, PET, and X-ray) are usually required [66-68]. Each imaging modality has unique properties with advantages and disadvantages; here, we will review these features as they relate to placement of biomaterials in the central nervous system (CNS).

\subsection{In vitro imaging of biomaterials}

Optical imaging (OI) is widely used for the in vitro assessment of cells, tissues, and biomaterials. In general, OI systems use visible, ultraviolet, or infrared light to interrogate tissue properties. Confocal microscopy (CM) is a fluorescence imaging technique that uses a laser for sample scanning. Due to limited depth penetration, CM is mostly used for in vitro studies, but with subcellular resolution, high sensitivity, and specificity, it allows studying the biomaterial's properties and offers the ability to track embedded cells in great detail. Raman et al. revealed that the addition of multiple fluorescent dyes into different hydrogel composites enabled discrimination of its microstructure in vitro [69]. Moreover, as was shown by Lee et al. [70], CM enabled 3D visualization of the migration of human dermal fibroblasts (HDF) embedded in degradable, biomimetic (GGGLGPAGGK-PEG) hydrogels.

Another OI technique is two-photon fluorescence microscopy (TPFM), which enhances the depth of sample penetration. Recently, the TPFM has been used to evaluate the 3D structure of various hydrogels. The TPFM provided reliable measurements of the network and pore sizes of the hydrogels [71]. Furthermore, Kim et al. [72] established that C2C12-expressing myoblasts could be imaged and differentiated in 3D gelatin hydroxyphenylpropionic acid (GHPA) hydrogels, using multiphoton excitation fluorescence microscopy. The outstanding spatial resolution of several hundreds of nanometers enables the ability to obtain high-resolution images of the cells, cultured inside the hydrogels.

Near infrared (NIR) microscopy is another OI modality suitable for imaging hydrogel structure and integrity, with the main advantage of improved light penetration that allows for imaging at greater depth. Cho et al. demonstrated non-invasive in vitro and in vivo tracking of hydrogels labeled with ICG for drug delivery in mice [73]. NIR light penetrates an organism efficiently, which makes this method promising for in vivo imaging of biomaterials. $\mathrm{Xu}$ et al. [74] demonstrated the possibility of NIR/pH-responsive monitoring of a poly(NIPAm-Co-MPCD)/GNRs nanocomposite hydrogel in vitro and in vivo in targeted cancer therapy in a mouse model.

For further comprehensive characterization of both the surface and inside structure of the hydrogels, as well as the pore size, electron microscopy techniques (e.g. TEM, cryo TEM, SEM) are very useful. Although they are usually used for ex vivo tissues and cell imaging, it has been shown that they are useful tools with which to study the details of hydrogels and other biomaterials [75].

\subsection{Modalities suitable for in vivo imaging of biomaterials}

\subsubsection{Bioluminescence}

Bioluminescence imaging (BLI) is based on a reporter gene e.g. firefly luciferase, that is genetically introduced into the cells of interest. As the photon signal is generated only by metabolically active cells and is dependent on access to ATP, it is very informative and widely used method for in vivo monitoring of cell viability in small animal models. As described by Allen et al. [76], BLI may be useful for the estimation of cell viability inside the hydrogels. GFP/Luc hMSCs were embedded in (low-molecular-weight-irradi ated RGD-functionalized) alginate or in (SeaPlaque) agarose hydrogels and injected subcutaneously in rats. Although both hydrogel types showed a linear correlation between the BLI signal and the live cell number using a 30-min imaging protocol, there was a dif- 
ference in the magnitude of the BLI signal measured between the agarose and alginate materials, exemplifying the utility of BLI for monitoring interactions between biomaterials and embedded cells. In addition, Liang et al. [10] showed that BLI is useful for monitoring the viability of cells embedded in injectable hydrogel. That study showed that HA-based hydrogels improved the survival and proliferation of three different transplanted cell lines (C17.2 neural stem cells, ReNcells, and glial progenitors). Similarly, Levit et al. [77] used Luc hMSCs encapsulated in a low-viscosity guluronic acid-based alginate (LVG, Novamatrix) in a rat myocardial infarction (MI) model. BLI showed that encapsulation of MSCs in an LVG hydrogel minimized scar formation and improved cardiac function. Similarly, luciferase-expressing adipose stem cells (Luc ASCs) embedded within fibrin scaffolds and transplanted in the injured heart were tracked with BLI for 14 days, as reported by Yang et al. [78].

Overall, BLI of biomaterials with embedded stem cells is straightforward, feasible, and reliable when used in small animals. One important limitation is light absorption and scattering, precluding the application of this technique in large animals or humans.

\subsubsection{Ultrasound}

The conventional ultrasound (US) imaging system has been widely used for years for vascular flow or soft tissue imaging. However, there are many examples of its application to the study of biomaterials. US transmits ultrasound waves generated by a one-piece or an array transducer and the waves are reflected, backscattered, returned, and received by the same transducer. Then, based on the time required for the wave to echo back and the strength of the received signal, an image is generated [59]. While the application of ultrasound for the imaging of the spinal cord is challenging due to surrounding bone, which is a somewhat impenetrable barrier for US waves, it is possible to use it in neonates or as an intraoperative procedure. We will provide here examples of US imaging of biomaterials outside the CNS. US can facilitate the non-invasive imaging of the mechanical and morphological properties of distributed biomaterials in vivo and in vitro, without the necessity of contrast agents. Gudur et al. [79] reported the utility of spectral US to study collagen-based scaffolds with embedded mineral particles. The spectral US provided information about the biomaterials, as well as the size, morphology, concentration, distribution, and size of embedded particles. Moreover, US has been used for the noninvasive, long-term in vivo observation of the mechanical properties of polyurethane scaffolds implanted intramuscularly in the rat [80]. Other well-developed systems using ultrasound are high-intensity focused ultrasound (HIFU) and doped ultrasound elastometry (DUE). It was reported by Jeong et al. that PEGylated liposomal indocyanine green (LCLP-ICG) and PEGylated liposomal doxorubicin (LCLP-Dox) can be coupled with HIFU/NIR to track drug release in solid tumors in a mouse model [81]. The doped ultrasound elastometry (DUE) was established for the evaluation of the microstructure of an HA-based hydrogel alone and preosteoblast-seeded hydrogel constructs [82]. The application of DUE provided insight into the spatial variation of viscoelastic properties at sub-millimeter resolution without the necessity for any contrast agents.

\subsubsection{Photoacoustics}

Another technique based on the US mechanism, which may be used for the study of biomaterials, is photoacoustic imaging [9]. In photoacoustics, short pulses of near-infrared energy are delivered to an object and absorbed optical energy is released as heat, leading to further emission of ultrasonic waves that can be detected by the US transducer [83] The multimodal system of US and photoacoustics was used to monitor transplanted cells and biomaterials in vitro and in vivo. Chung et al. [84] reported that US/photoacous- tics allowed determination of the size and shape of PEG-fibrin hydrogels, as well as detection of embedded ASC labeled with nanoscale gold spheres (AuNT; $20 \mathrm{~nm}$ ) at different time points in vitro. The US/photoacoustics system has also been successfully used for in vivo longitudinal monitoring of hydrogel-embedded stem cells. The PEGylated fibrin hydrogels with Au-NT-labeled MSCs, injected intramuscularly into rat hind limbs, were easily distinguished from the background when the combination of US/PAM was used, but were barely visible by US alone [85]. Furthermore, Yoon et al. demonstrated that it is feasible to visualize ICG-HSAPAA nanoparticles using a custom-made photoacoustic system inside biopolymer tubes that imitated blood vessels [86].

\subsubsection{Magnetic resonance imaging (MRI)}

MRI has many features that make it one of the most desirable and preferable imaging modalities for both in vitro and in vivo imaging. These features include superior soft tissue contrast, tomographic capabilities, anatomical details, and it is non-invasive and radiation-free. MRI has been widely used for in vivo and ex vivo analysis of biomaterials and transplanted cells, and, while detection of native components of hydrogel has been demonstrated [87], labeling with MRI contrast agent is usually required.

Iron oxide [88] gadolinium [89] and fluorine [90] are, by far, the most frequently used contrast agents. Superparamagnetic Iron Oxide Nanoparticles (SPION) are of particular interest for clinical studies, since they, in general, do not result in adverse effects on cell survival and functionality in terms of differentiation capacity, gene expression profiles, or migratory capacity [44,91]. Bigini et al. [92] labeled human fetal cells (hAFCs) with SPIO nanoparticles in the brain of mice with motor neuron disease. It was reported that transplanted cells rapidly diffused throughout the fourth ventricle at the level of the spinal cord, and the labeling did not affect the proliferation and metabolic activity of cells. MRI has been successfully used for the dynamic assessment of cell biodistribution in real-time during intraarterial injection in rodents [9] where imaging was instrumental in optimizing the procedure of cell delivery. Recently, real-time MRI monitoring has been applied to predict and improve the precision of cell delivery into the brain in small- and large-animal models [5].

MRI has also been instrumental in the assessment of biomaterials. Yang et al. [93] reported that the biodegradability level of hydrogels may be monitored and quantified in vivo using an alteration of ${ }^{19} \mathrm{~F}$ intensity. Recently, MR imaging of hydrogels transplanted as scaffolds, as well as an injectable formulation, has been reported [94]. Zhang et al. [95] presented in situ, crosslinkable, HA-based hydrogels, hybridized with iron oxide nanoparticles to enable their detection on MRI. Another interesting study used iron oxide as a contrast agent and multiple crystals of iron oxide were encapsulated inside the polyacrylamide matrix, yielding very high relaxivity. Because of the monitoring of the amount of liberated iron oxide nanoparticles by the hyaluronidases, it was possible to monitor and analyze the hydrogel degradation [96]. Bible and co-workers [21] showed non-invasive imaging of the ECM scaffold in a stroke-damaged rat brain using ${ }^{19} \mathrm{~F}$ MRI, demonstrating that transplantation of neural stem cells embedded in xenogeneic extracellular matrix (ECM) scaffolds resulted in uniformly distributed cells throughout the lesion cavity. Recently Ghuman et al. [97] showed possibility of use ECM-based hydrogels in rodent stroke model. They implant different concentrations of hydrogel into 14 days old stroke cavity and perform MR imaging up to 90 days post transplantation. This study showed that ECM-based hydrogel lead to brain tissue regeneration. Another work by Wang et al. [98] use hydrogel loaded with multiple drugs in spinal cord injury (SCI). Use of CAQK-LIP-GFs/DTX@HP treatment markedly enhanced the recovery of the injured spinal cords compared to injury without multi drug treatment. Moreover, there is growing interest in anti- 
cancer drug-loaded hydrogels. Bastiancich and co-workers [99] used this type of biomaterial in model of glioblastoma (GBM) in rats. They showed that GemC12-LNC hydrogels is promising and safe for the local treatment of operable GBM tumors.

Notably, group of Bermejo-Velasco [100] prepared gadolinium (Gd)-labeled hyaluronic acid (HA) hydrogel and showed possibility to visualize it using magnetic resonance. They report that degradation of that hydrogel can be followed using MR imaging.

Chemical exchange saturation transfer MRI (CEST-MRI) is a molecular MRI technique with the important advantage that components which naturally occur in the biomaterials are used to generate contrast [101]. Endogenous molecules dependent on the content of labile protons in the sample may generate CEST contrast, thus facilitating their detection by CEST MRI without any additional contrast agent. Liang et al. [60] reported on the use of CEST MRI to monitor biodegradation of a gelatin containing HA-based hydrogels, both in vitro as well as in vivo in mice. In addition, Jin et al. [102] described the use of CEST for both in vitro and in vivo examination of extracellular matrix (ECM) hydrogels in a rat stroke model. In vitro CEST imaging was instrumental in demonstrating dynamic changes in the different components of the ECM inside the hydrogel. Moreover, in vivo CEST examination allowed detection of ECM hydrogel distribution and degradation that strongly corresponded to histological studies post mortem. Chan et al. [66] described $\mathrm{pH}$ nanosensor-based magnetic resonance imaging as a modality with which to image encapsulated cell death in vivo. Ultrapure, low-viscosity, high-guluronate alginate and ultrapure, low-viscosity, high-mannuronate alginate (NovaMatrix), and liposomes containing L-arginine, were used for microcapsule preparation. It was shown that LipoCEST nanosensors were sensitive enough to detect cell death caused by incomplete immunoprotection of hydrogels in cell therapies. This technology can be easily translatable to the clinic based on the addition of biodegradable CEST liposomes and the easy access to MRI scanners. Group of Shazeeb [103] used CEST MRI to investigate in vivo degradation profiles of hyaluronic acid based hydrogels over three months. They showed unique possibility of using CEST MRI to optimization of hydrogels to different applications in regenerative medicine.

\subsubsection{PET/SPECT}

Nuclear imaging techniques are based on the use of radiotracers that can be used to label cells or biomaterials prior to their implantation. Due to their high sensitivity, Positron Emission Tomography (PET) and Single Positron Emission Computed Tomography (SPECT) are widely used in clinical and laboratory research. Interest in PET is growing due to the relatively high resolution and fast image acquisition, with low toxicity. The most popular PET radiotracer is Fluorine $\left({ }^{18} \mathrm{~F}\right)$, widely used for clinical applications. Both PET and SPECT have been used to image biomaterials [25]. In a rabbit model, SPECT imaging of 99mTc-MDP-labeled MSCs, embedded in porous b-TCP scaffolds, enabled monitoring of the metabolism and vascularization of tissue-engineered bone [61]. Likewise, in vivo PET imaging facilitated longitudinal monitoring of the ${ }^{18} \mathrm{FDG}$-labeled, cardiac-derived stem cells embedded in fibrin glue transplanted intramuscularly [104]. In addition, ${ }^{18} \mathrm{FDG}$ and ${ }^{18} \mathrm{Na}$ labeling of gellan gum and a kappa-carrageenan hydrogel was useful for intraoperative and short-term post-operative imaging of biomaterial distribution. Prolonged signal detection was observed when radiotracers were added into hydrogels with no significant cytotoxic effect [105]. Moreover, Fernandez-Ferreiro et al. revealed that PET enabled observation of the [18F]FPCA-F9-labeled hydrogel degradation process in addition to the slow release of a radiotracer on the ocular surface of the rat [106]. The technetium-99 m labeling of nanofibrillar cellulose hydrogels (NFC) was used to track hydrogel-embedded drug delivery in mice [62].
3.4.6. X-ray

$\mathrm{X}$-ray is the oldest imaging technique still widely used in a clinical setting. A more advanced modality that uses $\mathrm{x}$-ray radiation is computed tomography (CT). While most applications of $\mathrm{x}$-ray for imaging of hydrogels utilize a contrast agent, there are some reports on the imaging of native biomaterials. X-ray imaging based on phase contrast proved to be capable of detecting the hydrogel structure without the addition of contrast agent. The nonporous and porous PEG hydrogels were discernible from surrounding water or soft tissue in vitro without the use of contrast agents [107]. In addition, Faraj et al. [108] demonstrated that high-resolution computed tomography (micro-CT) enables the determination of the structure of soft scaffolds in vitro. In addition to low X-ray attenuation of collagen-based hydrogels, different combinations of contrast agents were used. It was shown that the application of osmium tetroxide and uranyl acetate, or a combination of uranyl acetate and lead citrate, allowed high-resolution 3D imaging of the structure of the scaffolds. Lei et al. [109] showed the possibility of non-invasive tracking of radiopaque thermo-reversible hydrogels after implantation, and the opportunity to obtain detailed 3D morphological information in a real-time manner. During the first week after implantation, animals had daily micro CT scans, which clearly showed the presence of biomaterial in the abdomen. Likewise, Appel et al. [110] showed that XPC CT application allows 3D visualization and quantification of hydrated soft tissues and PEG hydrogels in vivo, with no contrast agents. The XPC CT imaging enabled a clear distinction between surrounding tissue after transplantation and the hydrogel structure. Also, tantalum, known for its biological properties of facilitating soft tissue regeneration and vascularization, is, at the same time a promising contrast agent for X-ray imaging, enhancing the visibility of cells and biomaterial grafts [111]. The group of Wu and co-workers [112] showed CT and PA dual-model imaging feature to localization of AMD (Agar/MBP/DOX) hydrogel within tumor. Moreover great advantage of this modality is that the tumor therapy efficacy can be promoted to a great extent. Due to its accessibility and low cost, X-ray imaging techniques are promising tools for hydrogel observation.

\subsubsection{Optical coherence tomography}

High-resolution images of hydrogels may also be obtained using optical coherence tomography (OCT). OCT has been broadly used to image cell distribution and migration within hydrogels in vitro and in vivo [113]. Zheng et al. demonstrated [114] the feasibility of 3D OCT imaging for assessing both the scaffold architecture of poly (lactide-co-glycolide) and HEK cell distribution inside those biomaterials. In addition, OCT was applied to the in vitro and in vivo imaging of hydrogels injected subcutaneously in pigs and in humans. Label-free OCT imaging was used to visualize the surface, and 3D imaging of hydrogel-based micro-needles within skin layers [115]. OCT was also shown to be a promising tool for the tracking of intraocular surgical procedures. Childs et al. indicated that OCT may be an optimal technique for the non-invasive assessment of hydrogel-based contact lenses [116].

The aforementioned techniques, broadly used for diagnostic examinations in clinics, also provide the ability to non-invasively monitor hydrogels, as well as the cells embedded within the hydrogels, both in vitro and in vivo. Nevertheless, every mentioned system has its own limitations due to the sample thickness, the necessity of contrast agent usage, or the toxicity of the chemicals used. The possible solution for some of those limitations may be multimodal imaging that will allow tracking of hydrogel properties and which delivery method is suitable for the treatment of various disorders. OCT was a valuable tool for in-vivo monitoring of retinal structure in cases operated with hyaluronic acid ( 1 and 2,2\%) as a vitreous body substitutes in work by Schnichels et al. [117]. Moreover, combining different imaging techniques, such as PET/MRI 
may provide an accurate anatomical (from MR) and high sensitivity, quantitative (PET) data based on PET reporters [118,119] or macromolecules [119]. Combining multiple modalities for synergistic information is also possible as biomaterials with bi- and even trimodal contrast can be synthesized. One practical disadvantage could be the cost and logistical difficulties so potential benefits should always outweigh that cost.

\section{Outlook for the use of bioinks for regenerative approaches in neurological applications}

Therapies for neurological disorders based on stem cell transplantation proved to be challenging. The structural complexity of the CNS makes it overwhelming for injected stem cells to appropriately assemble into these complex functional units and reach their full potential, due to the limitations previously referred. While some beneficial effects have been reported, improvements are rather small and broad clinical adaptation will depend on further optimization. We postulate that interfacing stem cells with biomaterials and imaging techniques is required to achieve further progress in regenerative medicine for brain repair. Bioprinting technology is mature enough to consider building these complex functional units de novo. The availability of a variety of bioinks with good biocompatibility and biomechanical properties enables opportunity for creating artificial tissues. In addition, the available hardware that supports printing with various types of live cells, which can then be arranged into complex artificial tissues with appropriate site-specific cytoarchitecture opens up new avenues to study repair strategies for damaged nervous tissue. Various imaging techniques and reconstruction strategies can be used for ex vivo tissue bioprinting. This is currently utilized and hopefully will be developing further in near future. Also, non-invasive imaging facilitates monitoring the status of transplanted cells, the biodistribution, functional integration of implanted artificial tissue, and the biodegradation rate of the biomaterial. Pre-printing of tissue composites before their implantation is clearly feasible, but perhaps these complex artificial tissue structures can be soon printed in situ after gaining surgical access to the target site. The intraoperative tissue printing would be a revolutionary solution for pushing forward a personalized treatment, especially in delicate CNS environment. Direct bioprinting on the patient may provide the advantage of improved integration and bonding with surrounding tissues. Moreover, surgical examination with intraoperative imaging modalities can help optimizing protocols for boosting the regenerative potential of currently available stem cells with biomaterials products. Various imaging techniques provide useful information, from those rather limited to applications in small animal models (fluorescence, bioluminescence imaging) to clinically applicable (PET, MRI). Image-guided bioprinting and visualization of the printing process in real-time, in 3D in the context surrounding tissues would provide ultimate precision and control helping surgeons with precise placement of the graft. The improvement in the reproducibility and precision of artificial neural tissue deployment, as well as the longitudinal monitoring of graft performance, would substantially enhance the therapeutic success of tissue engineering approaches.

\section{Acknowledgments}

This work was supported by NanoTech4ALS (ref. ENMed/0008/2015, 13/EuroNanoMed/2016), funded under the EU FP7 M-ERA.NET program and Strategmed 1/233209/12/ NCBIR/2015. We would like to thank I-Hsun Wu for preparation of figures.

\section{Disclosures}

The authors declare no competing interest.

\section{References}

[1] A.M. Hopkins, E. DeSimone, K. Chwalek, D.L. Kaplan, 3D in vitro modeling of the central nervous system, Prog. Neurobiol. 125 (2015) 1-25.

[2] X. Ma, J. Liu, W. Zhu, M. Tang, N. Lawrence, C. Yu, M. Gou, S. Chen, 3D bioprinting of functional tissue models for personalized drug screening and in vitro disease modeling, Adv. Drug Deliv. Rev. 132 (2018) 235-251.

[3] J.H. Chin, N. Vora, The global burden of neurologic diseases, Neurology 83 (4) (2014) 349-351.

[4] H. Nomura, C.H. Tator, M.S. Shoichet, Bioengineered strategies for spinal cord repair, J. Neurotrauma 23 (3-4) (2006) 496-507.

[5] A. Lyczek, A. Arnold, J. Zhang, J.T. Campanelli, M. Janowski, J.W. Bulte, P. Walczak, Transplanted human glial-restricted progenitors can rescue the survival of dysmyelinated mice independent of the production of mature compact myelin, Exp. Neurol. 291 (2017) 74-86.

[6] M.F. Azari, L. Mathias, E. Ozturk, D.S. Cram, R.L. Boyd, S. Petratos, Mesenchymal stem cells for treatment of CNS injury, Curr. Neuropharmacol. 8 (4) (2010) 316-323.

[7] R.Y. Tam, T. Fuehrmann, N. Mitrousis, M.S. Shoichet, Regenerative therapies for central nervous system diseases: a biomaterials approach, Neuropsychopharmacology 39 (1) (2014) 169-188.

[8] M. Thomas, S.M. Willerth, 3-D bioprinting of neural tissue for applications in cell therapy and drug screening, Front. Bioeng. Biotechnol. 5 (2017) 69.

[9] A. Andrzejewska, A. Nowakowski, M. Janowski, J.W. Bulte, A.A. Gilad, P. Walczak, B. Lukomska, Pre- and postmortem imaging of transplanted cells, Int. J. Nanomed. 10 (2015) 5543-5559.

[10] Y. Liang, P. Walczak, J.W. Bulte, The survival of engrafted neural stem cells within hyaluronic acid hydrogels, Biomaterials 34 (22) (2013) 5521-5529.

[11] P.P. Tam, M.F. Pera, Stem cell science and regenerative medicine, BioEssays 35 (3) (2013) 147-148.

[12] J.R. Krieger, M.E. Ogle, J. McFaline-Figueroa, C.E. Segar, J.S. Temenoff, E.A. Botchwey, Spatially localized recruitment of anti-inflammatory monocytes by SDF-1alpha-releasing hydrogels enhances microvascular network remodeling, Biomaterials 77 (2016) 280-290.

[13] R. Lozano, L. Stevens, B.C. Thompson, K.J. Gilmore, R. Gorkin 3rd, E.M. Stewart, M. in het Panhuis, M. Romero-Ortega, G.G. Wallace, 3D printing of layered brain-like structures using peptide modified gellan gum substrates, Biomaterials 67 (2015) 264-273.

[14] F.Y. Hsieh, S.H. Hsu, 3D bioprinting: a new insight into the therapeutic strategy of neural tissue regeneration, Organogenesis 11 (4) (2015) 153-158.

[15] S.J. Lee, M. Nowicki, B. Harris, L.G. Zhang, Fabrication of a highly aligned neural scaffold via a table top stereolithography 3D printing and electrospinning, Tissue Eng. Part A 23 (11-12) (2017) 491-502.

[16] E. Oliveira, R.C. Assuncao-Silva, O. Ziv-Polat, E.D. Gomes, F.G. Teixeira, N.A Silva, A. Shahar, A.J. Salgado, Influence of different ECM-like hydrogels on neurite outgrowth induced by adipose tissue-derived stem cells, Stem Cells Int. 2017 (2017) 6319129.

[17] N.A. Silva, J. Moreira, S. Ribeiro-Samy, E.D. Gomes, R.Y. Tam, M.S. Shoichet, R. L. Reis, N. Sousa, A.J. Salgado, Modulation of bone marrow mesenchymal stem cell secretome by ECM-like hydrogels, Biochimie 95 (12) (2013) 2314-2319.

[18] Y.B. Lee, S. Polio, W. Lee, G. Dai, L. Menon, R.S. Carroll, S.S. Yoo, Bio-printing of collagen and VEGF-releasing fibrin gel scaffolds for neural stem cell culture Exp. Neurol. 223 (2) (2010) 645-652.

[19] I. Malysz-Cymborska, D. Golubczyk, L. Kalkowski, A. Burczyk, M. Janowski, P. Holak, K. Olbrych, J. Sanford, K. Stachowiak, K. Milewska, P. Gorecki, Z. Adamiak, W. Maksymowicz, P. Walczak, MRI-guided intrathecal transplantation of hydrogel-embedded glial progenitors in large animals, Sci. Rep. 8 (1) (2018) 16490.

[20] M. Barczewska, J. Wojtkiewicz, A. Habich, M. Janowski, Z. Adamiak, P. Holak, H. Matyjasik, J.W. Bulte, W. Maksymowicz, P. Walczak, MR monitoring of minimally invasive delivery of mesenchymal stem cells into the porcine intervertebral disc, PLoS One 8 (9) (2013) e74658.

[21] E. Bible, F. Dell'Acqua, B. Solanky, A. Balducci, P.M. Crapo, S.F. Badylak, E.T Ahrens, M. Modo, Non-invasive imaging of transplanted human neural stem cells and ECM scaffold remodeling in the stroke-damaged rat brain by (19)Fand diffusion-MRI, Biomaterials 33 (10) (2012) 2858-2871.

[22] Z. Wei, B.T. Harris, L.G. Zhang, Gelatin methacrylamide hydrogel with graphene nanoplatelets for neural cell-laden 3D bioprinting, Conf. Proc. IEEE Eng. Med. Biol. Soc. 2016 (2016) 4185-4188.

[23] I.T. Ozbolat, Bioprinting scale-up tissue and organ constructs for transplantation, Trends Biotechnol. 33 (7) (2015) 395-400.

[24] Y.S. Zhang, J. Yao, Imaging Biomaterial-Tissue Interactions, Trends Biotechnol 36 (4) (2018) 403-414.

[25] A.A. Appel, M.A. Anastasio, J.C. Larson, E.M. Brey, Imaging challenges in biomaterials and tissue engineering, Biomaterials 34 (28) (2013) 6615-6630.

[26] P.S. Gungor-Ozkerim, I. Inci, Y.S. Zhang, A. Khademhosseini, M.R. Dokmeci, Bioinks for 3D bioprinting: an overview, Biomater. Sci. 6 (5) (2018) 915-946.

[27] F. Fu, Z. Qin, C. Xu, X.Y. Chen, R.X. Li, L.N. Wang, D.W. Peng, H.T. Sun, Y. Tu, C. Chen, S. Zhang, M.L. Zhao, X.H. Li, Magnetic resonance imaging-three- 
dimensional printing technology fabricates customized scaffolds for brain tissue engineering, Neural Regen. Res. 12 (4) (2017) 614-622.

[28] E.S. Bishop, S. Mostafa, M. Pakvasa, H.H. Luu, M.J. Lee, J.M. Wolf, G.A. Ameer, T. C. He, R.R. Reid, 3-D bioprinting technologies in tissue engineering and regenerative medicine: current and future trends, Genes Dis. 4 (4) (2017) $185-195$.

[29] I.T. Ozbolat, W. Peng, V. Ozbolat, Application areas of 3D bioprinting, Drug Discov. Today 21 (8) (2016) 1257-1271.

[30] I.T. Ozbolat, K.K. Moncal, H. Gudapati, Evaluation of bioprinter technologies, Addit. Manuf. 13 (2017) 179-200.

[31] Z. Wang, R. Abdulla, B. Parker, R. Samanipour, S. Ghosh, K. Kim, A simple and high-resolution stereolithography-based 3D bioprinting system using visible light crosslinkable bioinks, Biofabrication 7 (4) (2015) 045009.

[32] K.S. Lim, R. Levato, P.F. Costa, M.D. Castilho, C.R. Alcala-Orozco, K.M.A. van Dorenmalen, F.P.W. Melchels, D. Gawlitta, G.J. Hooper, J. Malda, T.B.F. Woodfield, Bio-resin for high resolution lithography-based biofabrication of complex cell-laden constructs, Biofabrication 10 (3) (2018) 034101.

[33] H. Lin, D. Zhang, P.G. Alexander, G. Yang, J. Tan, A.W. Cheng, R.S. Tuan, Application of visible light-based projection stereolithography for live cellscaffold fabrication with designed architecture, Biomaterials 34 (2) (2013) 331-339.

[34] E.J. Mott, M. Busso, X. Luo, C. Dolder, M.O. Wang, J.P. Fisher, D. Dean, Digital micromirror device (DMD)-based 3D printing of poly(propylene fumarate) scaffolds, Mater. Sci. Eng. C Mater. Biol. Appl. 61 (2016) 301-311.

[35] I.T. Ozbolat, M. Hospodiuk, Current advances and future perspectives in extrusion-based bioprinting, Biomaterials 76 (2016) 321-343.

[36] K. Dubbin, A. Tabet, S.C. Heilshorn, Quantitative criteria to benchmark new and existing bio-inks for cell compatibility, Biofabrication 9 (4) (2017) 044102.

[37] B. Lorber, W.K. Hsiao, I.M. Hutchings, K.R. Martin, Adult rat retinal ganglion cells and glia can be printed by piezoelectric inkjet printing, Biofabrication 6 (1) (2014) 015001

[38] Q. Gu, E. Tomaskovic-Crook, R. Lozano, Y. Chen, R.M. Kapsa, Q. Zhou, G.C. Wallace, J.M. Crook, Functional 3D neural mini-tissues from printed gel-based bioink and human neural stem cells, Adv. Healthc. Mater. 5 (12) (2016) 14291438.

[39] W. Jia, P.S. Gungor-Ozkerim, Y.S. Zhang, K. Yue, K. Zhu, W. Liu, Q. Pi, B. Byambaa, M.R. Dokmeci, S.R. Shin, A. Khademhosseini, Direct 3D bioprinting of perfusable vascular constructs using a blend bioink, Biomaterials 106 (2016) 58-68.

[40] S. Knowlton, S. Anand, T. Shah, S. Tasoglu, Bioprinting for Neural Tissue Engineering, Trends Neurosci. 41 (1) (2018) 31-46.

[41] S.P. Tarassoli, Z.M. Jessop, A. Al-Sabah, N. Gao, S. Whitaker, S. Doak, I.S Whitaker, Skin tissue engineering using 3D bioprinting: an evolving research field, J. Plast. Reconstr. Aesthet. Surg. 71 (5) (2018) 615-623.

[42] A. Sarveazad, M. Bakhtiari, A. Babahajian, A. Janzade, A. Fallah, F. Moradi, M. Soleimani, M. Younesi, F. Goudarzi, J. Mohammad, Taghi, Comparison of human adipose-derived stem cells and chondroitinase ABC transplantation on locomotor recovery in the contusion model of spinal cord injury in rats, Iran J. Basic Med. Sci. 17 (9) (2014) 685-693.

[43] A. Abdanipour, T. Tiraihi, T. Taheri, Intraspinal transplantation of motoneuron-like cell combined with delivery of polymer-based glial cell line-derived neurotrophic factor for repair of spinal cord contusion injury, Neural Regen. Res. 9 (10) (2014) 1003-1013.

[44] M. Janowski, P. Walczak, T. Kropiwnicki, E. Jurkiewicz, K. Domanska-Janik, J. W. Bulte, B. Lukomska, M. Roszkowski, Long-term MRI cell tracking after intraventricular delivery in a patient with global cerebral ischemia and prospects for magnetic navigation of stem cells within the CSF, PLoS One 9 (2) (2014) e97631.

[45] N. Muja, M.E. Cohen, J. Zhang, H. Kim, A.A. Gilad, P. Walczak, T. Ben-Hur, J.W Bulte, Neural precursors exhibit distinctly different patterns of cell migration upon transplantation during either the acute or chronic phase of EAE: a serial MR imaging study, Magn. Reson. Med. 65 (6) (2011) 1738-1749.

[46] P. Walczak, A.H. All, N. Rumpal, M. Gorelik, H. Kim, A. Maybhate, G. Agrawal, J. T. Campanelli, A.A. Gilad, D.A. Kerr, J.W. Bulte, Human glial-restricted progenitors survive, proliferate, and preserve electrophysiological function in rats with focal inflammatory spinal cord demyelination, Glia 59 (3) (2011) 499-510.

[47] J.M. Oliveira, L. Carvalho, J. Silva-Correia, S. Vieira, M. Majchrzak, B. Lukomska, L. Stanaszek, P. Strymecka, I. Malysz-Cymborska, D. Golubczyk, L. Kalkowski, R.L. Reis, M. Janowski, P. Walczak, Hydrogel-based scaffolds to support intrathecal stem cell transplantation as a gateway to the spinal cord: clinical needs, biomaterials, and imaging technologies, NPJ Regen. Med. 3 (2018) 8.

[48] M. Hospodiuk, M. Dey, D. Sosnoski, I.T. Ozbolat, The bioink: a comprehensive review on bioprintable materials, Biotechnol. Adv. 35 (2) (2017) 217-239.

[49] K. Miller, K. Chinzei, G. Orssengo, P. Bednarz, Mechanical properties of brain tissue in-vivo: experiment and computer simulation, J. Biomech. 33 (11) (2000) 1369-1376

[50] S. Budday, R. Nay, R. de Rooij, P. Steinmann, T. Wyrobek, T.C. Ovaert, E. Kuhl, Mechanical properties of gray and white matter brain tissue by indentation, J. Mech. Behav. Biomed. Mater. 46 (2015) 318-330.

[51] J. Park, S.J. Lee, S. Chung, J.H. Lee, W.D. Kim, J.Y. Lee, S.A. Park, Cell-laden 3D bioprinting hydrogel matrix depending on different compositions for soft tissue engineering: characterization and evaluation, Mater. Sci. Eng. C Mater. Biol. Appl. 71 (2017) 678-684.
[52] F. Kreimendahl, M. Kopf, A.L. Thiebes, D.F. Duarte Campos, A. Blaeser, T. Schmitz-Rode, C. Apel, S. Jockenhoevel, H. Fischer, Three-dimensional printing and angiogenesis: tailored agarose-type I collagen blends comprise three-dimensional printability and angiogenesis potential for tissueengineered substitutes, Tissue Eng. Part C Methods 23 (10) (2017) 604-615.

[53] R.Y. Tam, M.J. Cooke, M.S. Shoichet, A covalently modified hydrogel blend of hyaluronan-methyl cellulose with peptides and growth factors influences neural stem/progenitor cell fate, J. Mater. Chem. 22 (37) (2012) 1940219411.

[54] S. Derakhshanfar, R. Mbeleck, K. Xu, X. Zhang, W. Zhong, M. Xing, 3D bioprinting for biomedical devices and tissue engineering: a review of recent trends and advances, Bioact. Mater. 3 (2) (2018) 144-156.

[55] V. Keriquel, F. Guillemot, I. Arnault, B. Guillotin, S. Miraux, J. Amedee, J.C. Fricain, S. Catros, In vivo bioprinting for computer- and robotic-assisted medical intervention: preliminary study in mice, Biofabrication 2 (1) (2010) 014101.

[56] H.W. Han, S.H. Hsu, Using 3D bioprinting to produce mini-brain, Neural Regen. Res. 12 (10) (2017) 1595-1596.

[57] N.A. Sears, D.R. Seshadri, P.S. Dhavalikar, E. Cosgriff-Hernandez, A Review of three-dimensional printing in tissue engineering, Tissue Eng. Part B, Reviews 22 (4) (2016) 298-310.

[58] F.Y. Hsieh, H.H. Lin, S.H. Hsu, 3D bioprinting of neural stem cell-laden thermoresponsive biodegradable polyurethane hydrogel and potential in central nervous system repair, Biomaterials 71 (2015) 48-57.

[59] S.Y. Nam, L.M. Ricles, L.J. Suggs, S.Y. Emelianov, Imaging strategies for tissue engineering applications, Tissue Eng. Part B, Reviews 21 (1) (2015) 88-102.

[60] B. Liang, Y. Ju, J.R. Joubert, E.J. Kaleta, R. Lopez, I.W. Jones, H.K. Hall Jr., S.N. Ratnayaka, V.H. Wysocki, S.S. Saavedra, Label-free detection and identification of protein ligands captured by receptors in a polymerized planar lipid bilayer using MALDI-TOF MS, Anal. Bioanal. Chem. 407 (10) (2015) 2777-2789.

[61] J. Zhou, H. Lin, T. Fang, X. Li, W. Dai, T. Uemura, J. Dong, The repair of large segmental bone defects in the rabbit with vascularized tissue engineered bone, Biomaterials 31 (6) (2010) 1171-1179.

[62] P. Lauren, Y.R. Lou, M. Raki, A. Urtti, K. Bergstrom, M. Yliperttula, Technetium99m-labeled nanofibrillar cellulose hydrogel for in vivo drug release, Eur. J. Pharm. Sci. 65 (2014) 79-88.

[63] M. Janowski, J.W. Bulte, P. Walczak, Personalized nanomedicine advancements for stem cell tracking, Adv. Drug Deliv. Rev. 64 (13) (2012) 1488-1507.

[64] J.C. Rasmussen, I.C. Tan, M.V. Marshall, C.E. Fife, E.M. Sevick-Muraca, Lymphatic imaging in humans with near-infrared fluorescence, Curr. Opin. Biotechnol. 20 (1) (2009) 74-82.

[65] A.R. Short, C. Czeisler, B. Stocker, S. Cole, J.J. Otero, J.O. Winter, Imaging cellmatrix interactions in 3D collagen hydrogel culture systems, Macromol. Biosci. 17 (6) (2017).

[66] K.W. Chan, G. Liu, X. Song H. Kim, T. Yu, D. R. Arifin, A.A. Gilad, J. Hanes, P. Walczak, P.C. van Zijl, J.W. Bulte, M.T. McMahon, MRI-detectable pH nanosensors incorporated into hydrogels for in vivo sensing of transplanted-cell viability, Nat. Mater. 12 (3) (2013) 268-275.

[67] K.W. Chan, T. Yu, Y. Qiao, Q. Liu, M. Yang, H. Patel, G. Liu, K.W. Kinzler, B. Vogelstein, J.W. Bulte, P.C. van Zijl, J. Hanes, S. Zhou, M.T. McMahon, A diaCEST MRI approach for monitoring liposomal accumulation in tumors, J. Controlled Release 180 (2014) 51-59.

[68] Y.K. Kim, M.H. Kim, D.H. Min, Biocompatible reduced graphene oxide prepared by using dextran as a multifunctional reducing agent, Chem. Commun. 47 (11) (2011) 3195-3197.

[69] R. Raman, N.E. Clay, S. Sen, M. Melhem, E. Qin, H. Kong, R. Bashir, 3D printing enables separation of orthogonal functions within a hydrogel particle, Biomed. Microdevices 18 (3) (2016) 49.

[70] S.H. Lee, J.J. Moon, J.L. West, Three-dimensional micropatterning of bioactive hydrogels via two-photon laser scanning photolithography for guided 3D cell migration, Biomaterials 29 (20) (2008) 2962-2968.

[71] L. Brigo, A. Urciuolo, S. Giulitti, G. Della Giustina, M. Tromayer, R. Liska, N. Elvassore, G. Brusatin, 3D high-resolution two-photon crosslinked hydrogel structures for biological studies, Acta Biomater. 55 (2017) 373-384.

[72] M.J. Kim, Y.C. Shin, J.H. Lee, S.W. Jun, C.S. Kim, Y. Lee, J.C. Park, S.H. Lee, K.D. Park, D.W. Han, Multiphoton imaging of myogenic differentiation in gelatinbased hydrogels as tissue engineering scaffolds, Biomater. Res. 20 (2016) 2.

[73] S.H. Cho, A. Kim, W. Shin, M.B. Heo, H.J. Noh, K.S. Hong, J.H. Cho, Y.T. Lim, Photothermal-modulated drug delivery and magnetic relaxation based on collagen/poly(gamma-glutamic acid) hydrogel, Int. J. Nanomed. 12 (2017) 2607-2620.

[74] S. Duan, Y. Yang, C. Zhang, N. Zhao, F.J. Xu, NIR-responsive polycationic gatekeeper-cloaked hetero-nanoparticles for multimodal imaging-guided triple-combination therapy of cancer, Small 13 (9) (2017).

[75] C.J. Medberry, P.M. Crapo, B.F. Siu, C.A. Carruthers, M.T. Wolf, S.P. Nagarkar, V. Agrawal, K.E. Jones, J. Kelly, S.A. Johnson, S.S. Velankar, S.C. Watkins, M. Modo, S.F. Badylak, Hydrogels derived from central nervous system extracellular matrix, Biomaterials 34 (4) (2013) 1033-1040.

[76] A.B. Allen, Z. Gazit, S. Su, H.Y. Stevens, R.E. Guldberg, In vivo bioluminescent tracking of mesenchymal stem cells within large hydrogel constructs, Tissue Eng. Part C Methods 20 (10) (2014) 806-816.

[77] R.D. Levit, N. Landazuri, E.A. Phelps, M.E. Brown, A.J. Garcia, M.E. Davis, G. Joseph, R. Long, S.A. Safley, J.D. Suever, A.N. Lyle, C.J. Weber, W.R. Taylor, 
Cellular encapsulation enhances cardiac repair, J. Am. Heart Assoc. 2 (5) (2013) e000367.

[78] J.J. Yang, Z.Q. Liu, J.M. Zhang, H.B. Wang, S.Y. Hu, J.F. Liu, C.Y. Wang, Y.D. Chen, Real-time tracking of adipose tissue-derived stem cells with injectable scaffolds in the infarcted heart, Heart Vessels 28 (3) (2013) 385-396.

[79] M. Gudur, R.R. Rao, Y.S. Hsiao, A.W. Peterson, C.X. Deng, J.P. Stegemann, Noninvasive, quantitative, spatiotemporal characterization of mineralization in three-dimensional collagen hydrogels using high-resolution spectral ultrasound imaging, Tissue Eng. Part C Methods 18 (12) (2012) 935-946.

[80] J. Yu, K. Takanari, Y. Hong, K.W. Lee, N.J. Amoroso, Y. Wang, W.R. Wagner, K. Kim, Non-invasive characterization of polyurethane-based tissue constructs in a rat abdominal repair model using high frequency ultrasound elasticity imaging, Biomaterials 34 (11) (2013) 2701-2709.

[81] H.S. Jeong, H. Hwang, P.S. Oh, E.M. Kim, T.K. Lee, M. Kim, H.S. Kim, S.T. Lim, M. H. Sohn, H.J. Jeong, Effect of high-intensity focused ultrasound on drug release from doxorubicin-loaded PEGylated liposomes and therapeutic effect in colorectal cancer murine models, Ultrasound Med. Biol. 42 (4) (2016) 947955.

[82] X. Hong, J.P. Stegemann, C.X. Deng, Microscale characterization of the viscoelastic properties of hydrogel biomaterials using dual-mode ultrasound elastography, Biomaterials 88 (2016) 12-24.

[83] L.V. Wang, S. Hu, Photoacoustic tomography: in vivo imaging from organelles to organs, Science 335 (6075) (2012) 1458-1462.

[84] E. Chung, S.Y. Nam, L.M. Ricles, S.Y. Emelianov, L.J. Suggs, Evaluation of gold nanotracers to track adipose-derived stem cells in a PEGylated fibrin gel for dermal tissue engineering applications, Int. J. Nanomed. 8 (2013) 325-336.

[85] S.Y. Nam, L.M. Ricles, L.J. Suggs, S.Y. Emelianov, In vivo ultrasound and photoacoustic monitoring of mesenchymal stem cells labeled with gold nanotracers, PLoS One 7 (5) (2012) e37267.

[86] H.K. Yoon, A. Ray, Y.E. Lee, G. Kim, X. Wang, R. Kopelman, Polymer-protein hydrogel nanomatrix for stabilization of indocyanine green towards targeted fluorescence and photoacoustic bio-imaging, J. Mater. Chem.B 1 (41) (2013).

[87] Y. Liang, A. Bar-Shir, X. Song, A.A. Gilad, P. Walczak, J.W. Bulte, Label-free imaging of gelatin-containing hydrogel scaffolds, Biomaterials 42 (2015) $144-150$.

[88] S.M. Cromer Berman, P. Walczak, J.W. Bulte, Tracking stem cells using magnetic nanoparticles, Wiley Interdiscip. Rev. Nanomed. Nanobiotechnol. 3 (4) (2011) 343-355.

[89] F.J. Nicholls, M.W. Rotz, H. Ghuman, K.W. MacRenaris, T.J. Meade, M. Modo, DNA-gadolinium-gold nanoparticles for in vivo T1 MR imaging of transplanted human neural stem cells, Biomaterials 77 (2016) 291-306.

[90] J.M. Janjic, E.T. Ahrens, Fluorine-containing nanoemulsions for MRI cell tracking, Wiley Interdiscip. Rev. Nanomed. Nanobiotechnol. 1 (5) (2009) 492501.

[91] D.A. Kedziorek, N. Muja, P. Walczak, J. Ruiz-Cabello, A.A. Gilad, C.C. Jie, J.W. Bulte, Gene expression profiling reveals early cellular responses to intracellular magnetic labeling with superparamagnetic iron oxide nanoparticles, Magn. Reson. Med. 63 (4) (2010) 1031-1043.

[92] P. Bigini, V. Diana, S. Barbera, E. Fumagalli, E. Micotti, L. Sitia, A. Paladini, C. Bisighini, L. De Grada, L. Coloca, L. Colombo, P. Manca, P. Bossolasco, F. Malvestiti, F. Fiordaliso, G. Forloni, M. Morbidelli, M. Salmona, D. Giardino, T. Mennini, D. Moscatelli, V. Silani, L. Cova, Longitudinal tracking of human fetal cells labeled with super paramagnetic iron oxide nanoparticles in the brain of mice with motor neuron disease, PLoS One 7 (2) (2012) e32326.

[93] X. Yang, Y. Sun, S. Kootala, J. Hilborn, A. Heerschap, D. Ossipov, Injectable hyaluronic acid hydrogel for $19 \mathrm{~F}$ magnetic resonance imaging, Carbohydr. Polym. 110 (2014) 95-99.

[94] J.I. Kim, B.S. Lee, C. Chun, J.K. Cho, S.Y. Kim, S.C. Song, Long-term theranostic hydrogel system for solid tumors, Biomaterials 33 (7) (2012) 2251-2259.

[95] Y. Zhang, Y. Sun, X. Yang, J. Hilborn, A. Heerschap, D.A. Ossipov, Injectable in situ forming hybrid iron oxide-hyaluronic acid hydrogel for magnetic resonance imaging and drug delivery, Macromol. Biosci. 14 (9) (2014) 12491259.

[96] B.A. Moffat, G.R. Reddy, P. McConville, D.E. Hall, T.L. Chenevert, R.R Kopelman, M. Philbert, R. Weissleder, A. Rehemtulla, B.D. Ross, A novel polyacrylamide magnetic nanoparticle contrast agent for molecular imaging using MRI, Mol. Imaging 2 (4) (2003) 324-332.

[97] H. Ghuman, C. Mauney, J. Donnelly, A.R. Massensini, S.F. Badylak, M. Modo, Biodegradation of ECM hydrogel promotes endogenous brain tissue restoration in a rat model of stroke, Acta Biomater. 80 (2018) 66-84.

[98] Q. Wang, H. Zhang, H. Xu, Y. Zhao, Z. Li, J. Li, H. Wang, D. Zhuge, X. Guo, H. Xu, S. Jones, X. Li, X. Jia, J. Xiao, Novel multi-drug delivery hydrogel using scarhoming liposomes improves spinal cord injury repair, Theranostics 8 (16) (2018) 4429-4446.

[99] C. Bastiancich, L. Lemaire, J. Bianco, F. Franconi, F. Danhier, V. Preat, G. Bastiat, F. Lagarce, Evaluation of lauroyl-gemcitabine-loaded hydrogel efficacy in glioblastoma rat models, Nanomedicine 13 (16) (2018) 1999-2013.

[100] D. Bermejo-Velasco, W. Dou, A. Heerschap, D. Ossipov, J. Hilborn, Injectable hyaluronic acid hydrogels with the capacity for magnetic resonance imaging, Carbohydr. Polym. 197 (2018) 641-648.

[101] E. Vinogradov, A.D. Sherry, R.E. Lenkinski, CEST: from basic principles to applications, challenges and opportunities, J. Magn. Reson. 229 (2013) 155172.

[102] T. Jin, F.J. Nicholls, W.R. Crum, H. Ghuman, S.F. Badylak, M. Modo, Diamagnetic chemical exchange saturation transfer (diaCEST) affords magnetic resonance imaging of extracellular matrix hydrogel implantation in a rat model of stroke, Biomaterials 113 (2017) 176-190.

[103] M.S. Shazeeb, R. Corazzini, P.A. Konowicz, R. Fogle, D.S. Bangari, J. Johnson, X. Ying, P.K. Dhal, Assessment of in vivo degradation profiles of hyaluronic acid hydrogels using temporal evolution of chemical exchange saturation transfer (CEST) MRI, Biomaterials 178 (2018) 326-338.

[104] J. Terrovitis, R. Lautamaki, M. Bonios, J. Fox, J.M. Engles, J. Yu, M.K. Leppo, M.G. Pomper, R.L. Wahl, J. Seidel, B.M. Tsui, F.M. Bengel, M.R. Abraham, E. Marban Noninvasive quantification and optimization of acute cell retention by in vivo positron emission tomography after intramyocardial cardiac-derived stem cell delivery, J. Am. Coll. Cardiol. 54 (17) (2009) 1619-1626.

[105] A. Fernandez-Ferreiro, J. Silva-Rodriguez, F.J. Otero-Espinar, M. GonzalezBarcia, M.J. Lamas, A. Ruibal, A. Luaces-Rodriguez, A. Vieites-Prado, T. Sobrino, M. Herranz, L. Garcia-Varela, J. Blanco-Mendez, M. Gil-Martinez, M. Pardo, A. Moscoso, S. Medin-Aguerre, J. Pardo-Montero, P. Aguiar, Positron emission tomography for the development and characterization of corneal permanence of ophthalmic pharmaceutical formulations, Invest Ophthalmol. Vis. Sci. 58 (2) (2017) 772-780.

[106] O. Morris, M.A. Elsawy, M. Fairclough, K.J. Williams, A. McMahon, J. Grigg, D. Forster, A.F. Miller, A. Saiani, C. Prenant, In vivo characterisation of a therapeutically relevant self-assembling (18) F-labelled beta-sheet forming peptide and its hydrogel using positron emission tomography, J. Labelled Compd. Radiopharm. 60 (10) (2017) 481-488.

[107] E.M. Brey, A. Appel, Y.C. Chiu, Z. Zhong, M.H. Cheng, H. Engel, M.A. Anastasio X-ray imaging of poly(ethylene glycol) hydrogels without contrast agents, Tissue Eng. Part C Methods 16 (6) (2010) 1597-1600.

[108] K.A. Faraj, V.M. Cuijpers, R.G. Wismans, X.F. Walboomers, J.A. Jansen, T.H. van Kuppevelt, W.F. Daamen, Micro-computed tomographical imaging of soft biological materials using contrast techniques, Tissue Eng. Part C Methods 15 (3) (2009) 493-499.

[109] H. Poort, C.A. Verhagen, M.E. Peters, M.M. Goedendorp, A.R. Donders, M.T. Hopman, M.W. Nijhuis-van der Sanden, T. Berends, G. Bleijenberg, H. Knoop, Study protocol of the TIRED study: a randomised controlled trial comparing either graded exercise therapy for severe fatigue or cognitive behaviour therapy with usual care in patients with incurable cancer, BMC Cancer 17 (1) (2017) 81.

[110] A.A. Appel, J.C. Larson, B. Jiang, Z. Zhong, M.A. Anastasio, E.M. Brey, X-ray phase contrast allows three dimensional, quantitative imaging of hydrogel implants, Ann. Biomed. Eng. 44 (3) (2016) 773-781.

[111] G. Mohandas, N. Oskolkov, M.T. McMahon, P. Walczak, M. Janowski, Porous tantalum and tantalum oxide nanoparticles for regenerative medicine, Acta Neurobiol. Exp. 74 (2) (2014) 188-196.

[112] C. Wu, J. Zhao, F. Hu, Y. Zheng, H. Yang, S. Pan, S. Shi, X. Chen, S. Wang, Design of injectable agar-based composite hydrogel for multi-mode tumor therapy, Carbohydr. Polym. 180 (2018) 112-121.

[113] S.B. Turturro, M.J. Guthrie, A.A. Appel, P.W. Drapala, E.M. Brey, V.H. PerezLuna, W.F. Mieler, J.J. Kang-Mieler, The effects of cross-linked thermoresponsive PNIPAAm-based hydrogel injection on retinal function, Biomaterials 32 (14) (2011) 3620-3626.

[114] K. Zheng, M.A. Rupnick, B. Liu, M.E. Brezinski, Three dimensional OCT in the engineering of tissue constructs: a potentially powerful tool for assessing optimal scaffold structure, Open Tissue Eng. Regener. Med. J. 2 (2009) 8-13.

[115] E.M. Vicente-Perez, H.L. Quinn, E. McAlister, S. O'Neill, L.A. Hanna, J.G. Barry, R.F. Donnelly, The use of a pressure-indicating sensor film to provide feedback upon hydrogel-forming microneedle array self-application in vivo, Pharm. Res. 33 (12) (2016) 3072-3080.

[116] A. Childs, H. Li, D.M. Lewittes, B. Dong, W. Liu, X. Shu, C. Sun, H.F. Zhang, Fabricating customized hydrogel contact lens, Sci. Rep. 6 (2016) 34905.

[117] S. Schnichels, N. Schneider, C. Hohenadl, J. Hurst, A. Schatz, K. Januschowski M.S. Spitzer, Efficacy of two different thiol-modified crosslinked hyaluronate formulations as vitreous replacement compared to silicone oil in a model of retinal detachment, PLoS One 12 (3) (2017) e0172895.

[118] C. Vandeputte, N. Evens, J. Toelen, C.M. Deroose, B. Bosier, A. Ibrahimi, A. Van der Perren, R. Gijsbers, P. Janssen, D.M. Lambert, A. Verbruggen, Z. Debyser, G. Bormans, V. Baekelandt, K. Van Laere, A PET brain reporter gene system based on type 2 cannabinoid receptors, J. Nucl. Med. 52 (7) (2011) 1102-1109.

[119] W.G. Lesniak, C. Chu, A. Jablonska, Y. Du, M.G. Pomper, P. Walczak, M. Janowski, PET imaging of intra-arterial (89)Zr bevacizumab in mice with and without osmotic opening of the blood-brain barrier: distinct advantage of intra-arterial delivery, J. Nucl. Med. (2018).

[120] T.J. Hinton, Q. Jallerat, R.N. Palchesko, J.H. Park, M.S. Grodzicki, H.J. Shue, M.H. Ramadan, A.R. Hudson, A.W. Feinberg, Three-dimensional printing of complex biological structures by freeform reversible embedding of suspended hydrogels, Sci. Adv. 1 (9) (2015) e1500758.

[121] Z. Tan, C. Parisi, L. Di Silvio, D. Dini, A.E. Forte, Cryogenic 3D printing of super soft hydrogels, Sci. Rep. 7 (1) (2017) 16293.

[122] O. Kerouredan, E.J. Ribot, J.C. Fricain, R. Devillard, S. Miraux, Magnetic resonance imaging for tracking cellular patterns obtained by laser-assisted bioprinting, Sci. Rep. 8 (1) (2018) 15777.

[123] J. Koffler, W. Zhu, X. Qu, O. Platoshyn, J.N. Dulin, J. Brock, L. Graham, P. Lu, J. Sakamoto, M. Marsala, S. Chen, M.H. Tuszynski, Biomimetic 3D-printed scaffolds for spinal cord injury repair, Nat. Med. 25 (2) (2019) 263-269.

[124] J.P. Morgan, P.F. Delnero, Y. Zheng, S.S. Verbridge, J. Chen, M. Craven, N.W. Choi, A. Diaz-Santana, P. Kermani, B. Hempstead, J.A. Lopez, T.N. Corso, C. Fischbach, A.D. Stroock, Formation of microvascular networks in vitro, Nat. Protoc. 8 (9) (2013) 1820-1836. 